\title{
Magnetic cationic liposomal nanocarriers for the efficient drug delivery of a curcumin-based vanadium complex with anticancer potential
}

\author{
Eleftherios Halevasa, ${ }^{b}$, Barbara Mavroidi ${ }^{b}$, Claudia H. Swanson ${ }^{c}$, Graham C. Smith ${ }^{c}$, \\ Alexandra Moschona ${ }^{d}$, Spyros Hadjispyrou ${ }^{e}$, Athanasios Salifoglou ${ }^{e}$, Anastasia A. Pantazaki ${ }^{f}$, \\ Maria Pelecanou ${ }^{b}$, George Litsardakis ${ }^{a}$ \\ a Laboratory of Materials for Electrotechnics, Department of Electrical and Computer Engineering, \\ Aristotle University of Thessaloniki, Thessaloniki 54124, Greece \\ b Institute of Biosciences \& Applications, National Centre for Scientific Research "Demokritos", 15310 \\ Athens, Greece

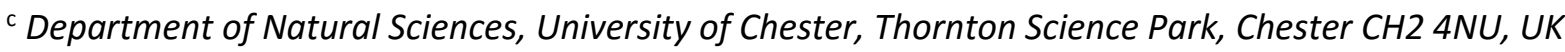 \\ ' Laboratory of Organic Chemistry, Department of Chemical Engineering, Aristotle University of \\ Thessaloniki, Thessaloniki 54124, Greece \\ e Laboratory of Inorganic Chemistry, Department of Chemical Engineering, Aristotle University of \\ Thessaloniki, Thessaloniki 54124, Greece \\ ${ }^{f}$ Laboratory of Biochemistry, Department of Chemistry, Aristotle University of Thessaloniki, \\ Thessaloniki 54124, Greece
}

Keywords:

Vanadium-curcumin complexes

Magnetic cationic liposomes

Drug encapsulation

Targeted drug delivery

DNA interaction

Anticancer potential

\begin{abstract}
In this work novel magnetic cationic liposomal nanoformulations were synthesized for the encapsulation of a crystallographically defined ternary V(IV)-curcumin-bipyridine (VCur) complex with proven bioactivity, as potential anticancer agents. The liposomal vesicles were produced via the thin film hydration method employing $\mathrm{N}$-[1-(2,3-dioleoyloxy)propyl]- $N, N, N$-trimethylammonium (DOTAP) and egg phosphatidylcholine lipids and were magnetized through the addition of citric acid surface-modified monodispersed magnetite colloidal magnetic nanoparticles. The obtained nanoformulations were evaluated for their structural and textural properties and shown to have exceptional stability and enhanced solubility in physiological media, demonstrated by the entrapment efficiency and loading capacity results and the in vitro release studies of their cargo. Furthermore, the generated liposomal formulations preserved the superparamagnetic behavior of the employed magnetic core maintaining the physicochemical and morphological requirements for targeted drug delivery applications. The novel nanomaterials were further biologically evaluated for their DNA interaction potential and were found to act as intercalators. The findings suggest that the positively charged magnetic liposomal nanoformulations can generate increased concentration of their cargo at the DNA site, offering a further dimension in the importance of cationic liposomes as nanocarriers of hydrophobic anticancer metal ion complexes for the development of new multifunctional pharmaceutical nanomaterials with enhanced bioavailability and targeted antitumor activity.
\end{abstract}

\section{Introduction}

Given the limitations of currently available chemotherapeutic approaches [1], magnetic drug targeting represents an innovative strategy that facilitates selective delivery and retention of various 
therapeutic agents at specific tissues [2-7]. In this approach, the prospective curative agents, bound to magnetic nanoparticles (MNPs) (ferrofluids) capable of responding to external magnetic fields, are effectively carried into the microcirculation of the tumor, thus minimizing drug accumulation in healthy peripheral tissues $[8,9]$. Among various types of nanoparticles (NPs), biocompatible superparamagnetic iron oxide (SPIO) NPs, with proper surface architecture, have attracted extensive attention, both for cellular imaging and drug delivery biomedical applications [10-14], due to their physical properties and biocompatible nature [15]. MNPs for biomedical applications should be hydrophilic and stable in water. Aqueous colloidal dispersions of MNPs hold great merit for use in diagnosis and treatment of diseases due to the: a) compatibility of the aqueous medium with the biosystem, b) controllable size distribution, c) uniform shape, d) strong magnetic susceptibility, e) directability induced by applied magnetic force, and f) capacity for surface functionalization with specific compounds and/or biomolecules [16-19].

One class of NPs with distinct advantages in drug delivery is liposomes (LPs). LPs are hollow colloidal microspheres, formed by curved bilayered membranes of self-aggregated lipids. LPs can entrap part of the aqueous medium in which they are suspended [20]. The amphiphilic character of lipids and their dense structural organization enable LPs to encapsulate hydrophobic compounds in the bilayer membrane and/or hydrophilic molecules in the internal aqueous cavity, as well as amphiphilic substances whose hydrophobic part anchors in the lipid bilayer and the polar part remains in the membrane polar region or in the internal aqueous phase [21]. Lately, MNPs have been combined with LPs in the development of integrated systems termed magnetic LPs or magnetoliposomes (MLPs) with remarkable potentials as fluorescent and imaging contrast agents or hyperthermia inducing agents $[22,23]$.

A more recent contribution to the field of targeted drug delivery involves the use of cationic LPs (CLPs) [24-27]. CLPs are generally employed as gene delivery systems due to their low immunogenicity and toxicity, size-independent delivery of nucleic acids, quality control, and ease of preparation [28]. CLPs, unlike their electroneutral and anionic counterparts, possess a fivefold enhanced targeted selectivity in tumor vessels over normal vessels in healthy tissues [29]. However, despite their preferential accumulation in tumors, they attain non-uniform distribution along tumor vessels. The combination of the electrostatic properties of CLPs with the application of magnetic drug targeting through the employment of MNPs can result in the formation of tumor specific delivery vehicles that can interact uniformly with the tumor vasculature and respond to an externally applied magnetic field [30].

Curcumin constitutes an excellent natural product for cancer treatment, however, its low aqueous solubility along with its rapid metabolism, poor absorption, and systemic elimination limit its bioavailability [31]. Curcumin-based metal complexes, not only help overcome the limited bioavailability of curcumin, but also exhibit significant biological activity demonstrating in many cases enhanced antitumor potential [32]. More specifically, oxovanadium(IV) complexes of curcumin with enhanced photocytotoxicity have been used as photosensitizers in PDT (photodynamic therapy), selectively activated at the photo-exposed cancer site in order to generate reactive oxygen species (ROS) [33-35].

In the present work, the third crystallographically reported oxovanadium(IV) complex of curcumin (VCur) (Fig. 1) with significant anti-ROS/anti-oxidant activity and DNA degradation potential [36] is encapsulated for the first time in magnetic cationic liposomal nanocarriers in the effort to create novel nanoformulations with targeted anticancer activity based on metal complexes of bioactive natural polyphenols.

In recent years, various studies have shown that incorporation of curcumin into LPs increases significantly its aqueous solubility and ameliorates its pharmacokinetic and bioavailability limitations. 
Liposomal curcumin has been reported to exhibit higher stability than free curcumin in phosphate buffered saline (PBS), human blood, plasma and cell culture media [37]. Moreover, curcumin-loaded LPs have been shown to induce apoptosis and suppress tumor proliferation and angiogenesis of several cancer cell lines by downregulating the nuclear factor kappa-light-chain-enhancer of activated B cells (NF-KB), and many anti-apoptosis proteins including B-cell lymphoma 2 (Bcl2), B-cell lymphoma-extra large (BcIXL), and cyclooxygenase-2 (COX-2) [38,39].

In the present study, the $\mathrm{N}$-[1-(2,3-dioleoyloxy)propyl]- $\mathrm{N}, \mathrm{N}, \mathrm{N}$-trimethylammonium (DOTAP) lipid will be employed in combination with egg L- $\alpha$-phosphatidylcholine (EPC) (Fig. 2) to form the CLPs. The combination of these lipids is known to produce liposomal structures that display high cellular uptake and retain the molecular integrity of their liposomal membranes under physiological conditions [40].

To the best of our knowledge, only one application of DOTAP-derived CLPS as nanocarriers of metal complexes has been reported in the literature. More specifically, CLPs were shown to be efficient nanocarriers for the transport of anticancer ruthenium complexes in cells significantly enhancing their stabilization in aqueous media, transport in cells, and anticancer activity [41-45]. Their successful but unique application indicates the necessity for the pursuit of further research on the generation of stable and long-life magnetic liposomal nanocarriers for the targeted delivery of metal-based anticancer drugs [41].

With the hope that investigation of the homogeneous dispersion and encapsulation of hydrophobic anticancer metal ion complexes in magnetic cationic liposomes (MCLPs) will enable development of new multifunctional pharmaceutical nanomaterials with enhanced bioavailability and targeted antitumor activity, this work for the first time a) evaluates and compares the anticancer efficiency and DNA-binding capacity of a crystallographically defined ternary V(IV)-curcumin-bipyridine complex (VCur) with proven bioactive efficacy [36] (Fig. 1), b) leads to the synthesis of citric acid (CA) surface-modified monodispersed magnetite (Fe3O4-CA) colloidal magnetic NPs (MNPs), c) develops MCLPs (mentioned henceforth as empty MCLPs, EMCLPs) via the thin film hydration method, $d$ ) evaluates and compares the suitability of these magnetic cationic liposomal vesicles as potential nanocarriers of VCur, (mentioned henceforth as VCur-loaded MCLPs, VCMCLPs), and e) investigates structural and textural properties of the encapsulated material through different and complementary characterization techniques.

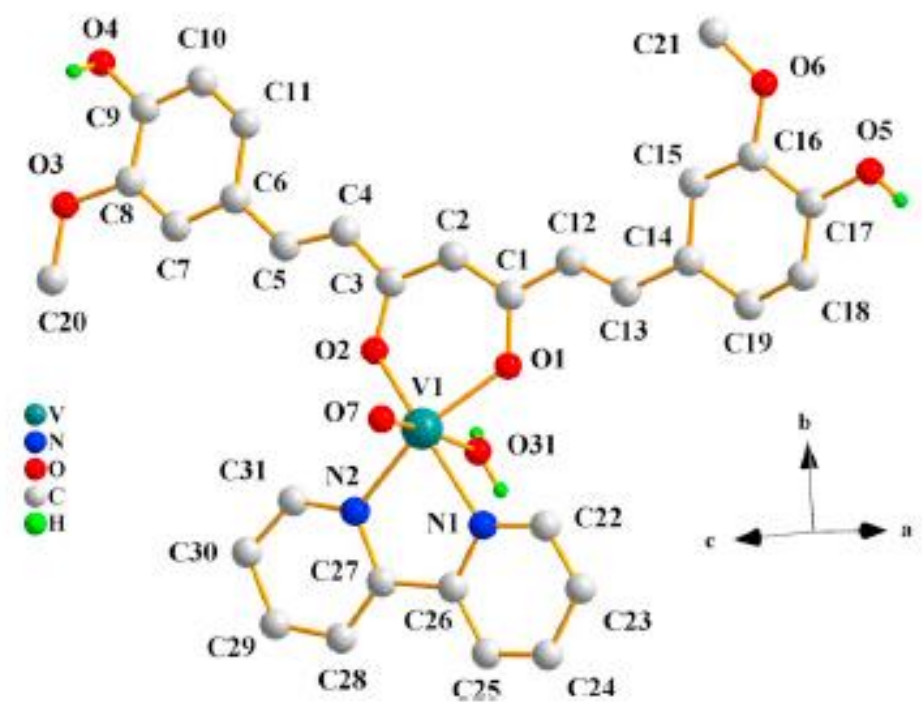

Fig. 1. Crystal structure of the V(IV)-curcumin-bipyridine complex (VCur) employed in this study. 


\section{Materials and methods}

\subsection{Materials}

The starting materials used include: Iron(II) chloride tetrahydrate $\left(\mathrm{FeCl}_{2} .4 \mathrm{H}_{2} \mathrm{O}\right)$, iron(III) chloride hexahydrate $\left(\mathrm{FeCl}_{3} .6 \mathrm{H}_{2} \mathrm{O}\right)$, ammonia solution ( $\left.25 \%\right)$, citric acid, curcumin, 2,2'-bipyridine, vanadyl sulphate trihydrate $\left(\mathrm{VOSO}^{4} \cdot 3 \mathrm{H}^{2} \mathrm{O}\right), \mathrm{N}$-[1-(2,3-dioleoyloxy)propyl]- $N, N, N$ trimethylammonium chloride (DOTAP chloride), egg L- $\alpha$-phosphatidylcholine (EPC) (Type XI-E, $100 \mathrm{mg} . \mathrm{ml}-1$ in chloroform, $\geq 99 \%$, solution), and PBS pH 7.4. These materials were purchased from commercial sources (Sigma, Fluka) and were used without further purification.

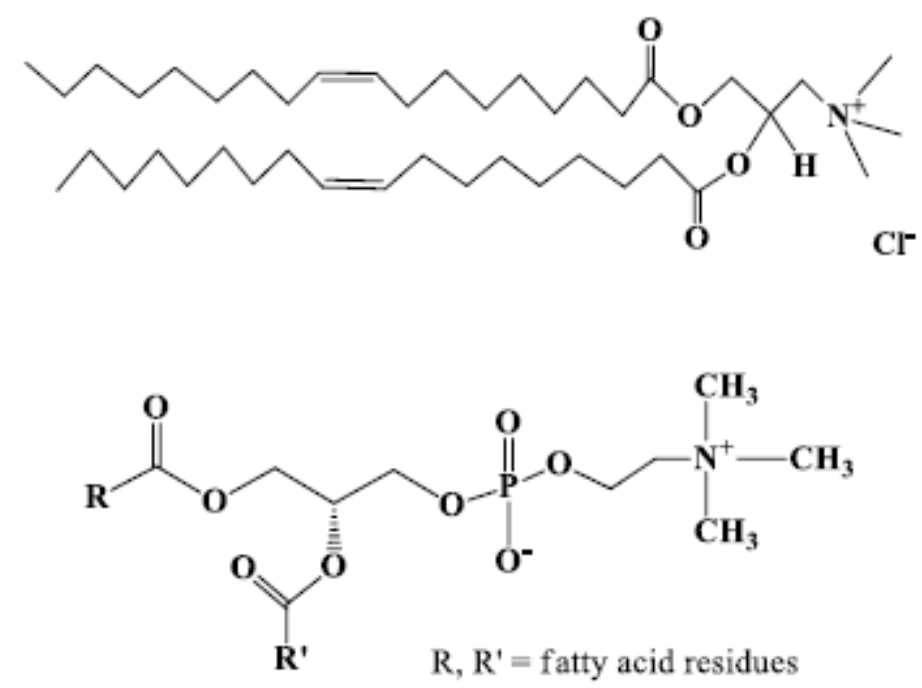

Fig.2. Schematic representation of the lipids employed in this study for the formation of CLPs.

Ultrapure water, chloroform, methanol $(\mathrm{MeOH})$, ethanol $(\mathrm{EtOH})$, and diethyl ether were used as solvents. Nitrogen gas was used for degassing ultrapure $\mathrm{H} 2 \mathrm{O}$ and for maintaining a nitrogen atmosphere during the synthetic procedures, where applicable. Calf thymus DNA (CT-DNA) was obtained from Sigma Aldrich (USA) and used as received. All DNA experiments were performed in phosphate buffer $(0.05 \mathrm{M}, \mathrm{pH} 7.2)$ prepared from $\mathrm{Na}^{2} \mathrm{HPO}^{4} \cdot 7 \mathrm{H}^{2} \mathrm{O}$ and $\mathrm{K}^{2} \mathrm{HPO}^{4}$. The CT-DNA solution was sufficiently free of protein as evidenced by the ratio of its UV absorbance at 260 and $280 \mathrm{~nm}$ that was approx. 1.9:1 [46]. The DNA concentration per nucleotide was determined spectrophotometrically by using the molar absorption coefficient of $\varepsilon=6600 \mathrm{M}-1 . \mathrm{cm}-1$ per nucleotide at $260 \mathrm{~nm}$. Stock solutions of CT-DNA were stored at $4{ }^{\circ} \mathrm{C}$ and were used within 4 days. Before measurements, all compounds and DNA were incubated for $24 \mathrm{~h}$ at $25^{\circ} \mathrm{C}$ to reach the equilibrium state. Before all DNA measurements, the mixtures of DNA-VCur or DNA-VCMCLPs were incubated for $24 \mathrm{~h}$ at $25^{\circ} \mathrm{C}$ to reach the equilibrium state. Each reported measurement value is the average of three independent experiments. Experimental stock solutions of VCur were made in dimethyl sulfoxide (DMSO) at a concentration of $10-3 \mathrm{M}$, and stored in the dark at $0-4^{\circ} \mathrm{C}$. Proper volumes from the VCur stock solution were added to achieve the desired ratios of $R=$ [compound]/[DNA].

The volumes required to reach the desired final concentrations of VCMCLPs in DNA solutions were determined based on the loading capacity of VCur in VCMCLPs (9.5\%, see Section 3.11 ) and the release studies (Section 3.12). In all DNA studies, the effect of the presence of Fe304-CA NPs and EMCLPs, that served as control, were assessed at ratios $\mathrm{R}=0.01,0.1$ and 0.5 .

\subsection{Characterization}

FT-Infrared spectra were recorded on a Perkin Elmer 1760X FT-infrared spectrometer. 
Crystal phase identification and relative percent composition in the synthesized materials were accomplished through X-ray diffraction (XRD) at ambient temperature on a Seifert XRD 3003-TT powder diffractometer using FeK $\alpha$ radiation in $2 \theta$ steps of $0.05^{\circ}$ for $4 \mathrm{~s}$.

Magnetization measurements on $\mathrm{Fe}_{3} \mathrm{O}_{4}-\mathrm{CA} N \mathrm{NP}, \mathrm{EMCLP}$ and VCMCLP dried powder samples were performed on a QD-Versalab VSM magnetometer, in fields up to $3 \mathrm{~T}$ and temperatures from $50 \mathrm{~K}$ to $400 \mathrm{~K}$.

High resolution transmission electron microscopy (HRTEM) images of $\mathrm{Fe}_{3} \mathrm{O}_{4}$-CA NPs were acquired using a FEI Tecnai G2-F30 S-Twin microscope operated at $300 \mathrm{kV}$. Small amounts of $\mathrm{Fe}_{3} \mathrm{O}_{4}-\mathrm{CA}$ NPs dispersed in $\mathrm{EtOH}$ were drop-cast on holey carbon-coated copper grids and subsequently air-dried before TEM analysis.

Transmission electron microscopy (TEM) images of EMCLPs and VCMCLPs were acquired using a Philips CM20 TEM, with particle size analysis performed manually with the assistance of ImageJ software. Samples were prepared for TEM analysis by sonicating the MCLPs in heptane, and pipetting a portion of the resulting mixture onto a holey carbon support film on 300 mesh copper TEM grid. This was allowed to dry in air, leaving a small amount of each sample on the grid ready for analysis. TEM images were obtained on a range of magnifications, using an accelerating voltage of $200 \mathrm{kV}$.

The surface chemistry of $\mathrm{Fe}_{3} \mathrm{O}_{4}$-CA NPs was investigated using a custom ultra-high vacuum X-ray photoelectron spectroscopy (XPS) system equipped with a $150 \mathrm{~mm}$ mean radius hemispherical energy analyzer (Specs GmbH Phoibos 150) and a monochromatic AlKa X-ray source at $1486.6 \mathrm{eV}$ (Specs GmbH Focus 500). The sample was prepared for XPS by drying onto clean Si(111) wafers, with data acquired as an area average over a region approximately $2 \mathrm{~mm}$ in diameter. Survey scans were performed with a pass energy of $50 \mathrm{eV}$ with scans over individual photoelectron lines performed at $15 \mathrm{eV}$. Data were quantified using Scofield cross sections [47], corrected for energy dependencies of the analyzer transmission and the effective electron attenuation lengths.

The morphology and detailed structural features of $\mathrm{Fe}_{3} \mathrm{O}_{4}$-CA NPs sample was investigated by scanning electron microscopy (SEM), using a high-resolution microscope FEI Quanta 3D FEG model, equipped with an energy dispersive X-ray (EDX) spectrometer Apollo X. The analyses were performed in high vacuum mode at different accelerating voltages $(5-20 \mathrm{kV})$, with the pellets being analyzed directly (samples were immobilized on a double-sided carbon tape, without coating). The microstructure of EMCLPs and VCMCLPs was analyzed using a Zeiss Leo 1455VP SEM equipped with Oxford Instruments INCA X-Act EDX detector and operated at $20 \mathrm{kV}$.

Mean particle size was determined through Dynamic Light Scattering (DLS) using Photon Correlation Spectroscopy (Malvern S4700 PCS System, Malvern Instruments Ltd, Malvern, UK). The analysis was performed at a scattering angle of $90 \mathrm{o}$ and at $25^{\circ} \mathrm{C}$, using samples appropriately dispersed in PBS ( $\mathrm{pH}$ 7.4). For each sample, the mean diameter \pm standard deviation of six determinations was calculated applying multimodal analysis. Values reported are the mean diameter [? $\}$ standard deviation for three replicate samples.

Zeta-potential measurements of Fe304-CA NP, EMCLP, and VCMCLP samples were taken by Laser Doppler Anemometry (Malvern Zetasizer IV, Malvern Instruments Ltd, Malvern, UK). All analyses were performed on samples appropriately diluted with $1 \mathrm{mM}$ PBS buffer (adjusted to pH 7.4) in order to maintain constant ionic strength. The refractive index and viscosity of the medium were set at 1.335 and 1.0200 , respectively [48]. For each sample, the mean value standard deviation of four 
determinations was established. Values reported are the mean value standard deviation for two replicate samples.

A Perkin Elmer, Pyris 1, system was used to run the simultaneous Thermogravimetric Analysis (TGA) experiments. The instrument mass precision is $1 \mu \mathrm{g}$. A specific amount $(\mathrm{mg})$ of each sample was placed in an open alumina sample pan for each experiment. High purity air was used at a constant flow rate of $30 \mathrm{~mL}$.min-1, depending on the conditions required for running the experiments. During the experiments, the sample weight loss and rate of weight loss were recorded continuously under dynamic conditions, as a function of time or temperature, in the range $30-850^{\circ} \mathrm{C}$. Prior to activating the heating routine program, the entire system was purged with the appropriate gas for $10 \mathrm{~min}$, at a rate of $30 \mathrm{~mL} . \mathrm{min}-1$, to ensure that the desired environment had been established.

Fe percentages were measured, after dissolving the samples in $\mathrm{HCl}$, by flame atomic absorption spectrophotometry (FAAS) using a Perkin Elmer AAnalyst 800 instrument.

The determination of entrapment efficiency and the in vitro release study of VCur were performed through High Performance Liquid Chromatography (HPLC) at a ThermoFinnigan Spectra HPLC system (San Jose, California) model UV 6000 LP, equipped with EZChromeElite software, Version 3.1.7., four Q-Grad pumps, a diode array detector (DAD) and a Grace Smart RP C-18 column (250×4.6mm id.; 5 $\mu \mathrm{m}$ particle size). The injection volume was $20 \mu \mathrm{L}$ and the wavelength used was $480 \mathrm{~nm}$. The mobile phases were $1 \%(\mathrm{v} / \mathrm{v})$ acetic acid in milli-Q $\mathrm{H} 2 \mathrm{O}$ (eluent $\mathrm{A}$ ) and $100 \% \mathrm{MeOH}$ (eluent $\mathrm{B}$ ) with a flow rate of $1 \mathrm{~mL}$.min-1. The elution profile was as follows: from $0 \mathrm{~min}, 100 \% \mathrm{~A} ; 25 \mathrm{~min}, 36 \% \mathrm{~A} / 64 \% \mathrm{~B} ; 35$ $\min , 25 \% \mathrm{~A} / 75 \% \mathrm{~B}$.

The freeze drying process of the EMCLPs and VCMCLPs was performed on a freeze dryer (Christ Alpha 1-2, Martin Christ Gefriertrocknungsanlagen $\mathrm{GmbH}$, Germany) coupled with a vacuum pump (rotary vane vacuum pump, Vacuumbrand RZ 2.5, Vacuumbrand GmbH t CO KG, Germany).

The ultrasonication procedure was performed on a probe sonicator (Heat Systems-Ultrasonics Inc., Sonicator W-375 Cell Disruptors). All measurements were performed immediately following material preparation.

\subsection{Synthesis of $\left[\mathrm{VO}\left(\mathrm{C}_{21} \mathrm{H}_{19} \mathrm{O}_{6}\right)\left(\mathrm{C}_{10} \mathrm{H}_{8} \mathrm{~N}_{2}\right)\left(\mathrm{H}_{2} \mathrm{O}\right)\right]_{2}\left(\mathrm{SO}_{4}\right) \cdot 2 \mathrm{CH}_{3} \mathrm{OH} .3 \mathrm{H}_{2} \mathrm{O}$}

The complex $\left[\mathrm{VO}\left(\mathrm{C}_{21} \mathrm{H}_{19} \mathrm{O}_{6}\right)\left(\mathrm{C}_{10} \mathrm{H}_{8} \mathrm{~N}_{2}\right)\left(\mathrm{H}_{2} \mathrm{O}\right)\right]_{2}\left(\mathrm{SO}_{4}\right) \cdot 2 \mathrm{CH}_{3} \mathrm{OH} .3 \mathrm{H}_{2} \mathrm{O}$ (VCur) (Fig. 1) was prepared and fully characterized according to previously reported work [36].

\subsection{Synthesis of monodisperse $\mathrm{Fe}_{3} \mathrm{O}_{4}-\mathrm{CA}$ colloidal MNPS}

$2.71 \mathrm{~g}(0.010 \mathrm{~mol})$ of $\mathrm{FeCl}_{3} \cdot 6 \mathrm{H}_{2} \mathrm{O}$ and $1.0 \mathrm{~g}$ of $\mathrm{FeCl}_{2} \cdot 4 \mathrm{H}_{2} \mathrm{O}(0.0050 \mathrm{~mol})$ were dissolved separately in two closed vessels containing $20 \mathrm{~mL}$ of degassed ultrapure $\mathrm{H} 2 \mathrm{O}$ pretreated for 30 min with inert nitrogen gas bubbling, and then mixed in a three-neck flask under a nitrogen atmosphere. The resulting solution was vigorously stirred at $90{ }^{\circ} \mathrm{C}$ under reflux for $60 \mathrm{~min}$ to avoid development of aggregates and large polycrystalline particles. Subsequently, $6 \mathrm{~mL}$ of ammonia solution were added drop by drop until pH 10.5. The resulting mixture was allowed to stir for $30 \mathrm{~min}$ at $90^{\circ} \mathrm{C}$ and then cooled to room temperature.

A black precipitate was obtained from the reaction mixture via magnetic separation by means of a permanent magnet and the supernatant was removed by decantation. The resulting $\mathrm{Fe}_{3} \mathrm{O}_{4} \mathrm{NPs}_{\mathrm{s}}$ were washed three times with ultrapure $\mathrm{H}_{2} \mathrm{O}$, resuspended in $20 \mathrm{~mL}$ of degassed ultrapure $\mathrm{H}_{2} \mathrm{O}$ in a threeneck flask under a nitrogen atmosphere. To that, $1.1 \mathrm{~g}(0.0060 \mathrm{~mol})$ of citric acid was added under 
vigorous stirring and the resulting mixture was stirred at $90{ }^{\circ} \mathrm{C}$ for $90 \mathrm{~min}$. Then, it was cooled to room temperature. Subsequently, $2 \mathrm{~mL}$ of ammonia solution was added until $\mathrm{pH} 7.5$ under continuous stirring and the mixture was stirred for another $80 \mathrm{~min}$ at $90^{\circ} \mathrm{C}$. A dark brown precipitate was collected by centrifugation at $9000 \mathrm{rpm}$ for $60 \mathrm{~min}$. The resulting $\mathrm{Fe}_{3} \mathrm{O}_{4}-\mathrm{CA} \mathrm{NPs}$ were washed three times with ultrapure $\mathrm{H}_{2} \mathrm{O}$ to remove the excess of $\mathrm{CA}$, and resuspended in $20 \mathrm{~mL}$ of degassed ultrapure $\mathrm{H}_{2} \mathrm{O}$ in order to form a ferromagnetic colloidal suspension of concentration $20 \mathrm{mg} \mathrm{Fe}_{3} \mathrm{O}_{4^{-}}$ CA NPs. $\mathrm{mL}^{-1} \mathrm{H}_{2} \mathrm{O}$. Subsequently, the suspension was stored in a closed dark vessel at $4^{\circ} \mathrm{C}$ for further use.

\subsection{Synthesis of VCMCLPS}

VCMCLPs were prepared according to the thin film hydration method $[49,50]$. More specifically, 21 $\mathrm{mg}$ of DOTAP chloride and $150 \mu \mathrm{L}$ of EPC ( $\approx 3: 2 \mathrm{~mol} / \mathrm{mol}$ ) (Fig. 2) were dissolved in $30 \mathrm{~mL}$ of a mixture of chloroform/methanol 2:1 (v/v) under continuous stirring at room temperature in a closed vessel. Subsequently, $10 \mathrm{mg}$ (7.10-6 mol) of VCur diluted in $15 \mathrm{~mL}$ of the same mixture of organic solvents was added to the above mixture under continuous stirring at room temperature in a $50 \mathrm{~mL}$ roundbottom flask at $\mathrm{a} \approx 7: 1$ total lipid/drug molar ratio $(\mathrm{mol} / \mathrm{mol})$. After complete homogenization of the mixtures, the organic phase was slowly removed at reduced pressure at $35^{\circ} \mathrm{C}$ using rotary evaporation, forming a crimson-colored thin lipid film on the inner side of the flask. The flask containing the lipid film was left for $2 \mathrm{~h}$ under high vacuum for the removal of any organic solvent traces. Subsequently, $2 \mathrm{~mL}$ of $\mathrm{Fe}_{3} \mathrm{O}_{4}$-CA NPs aqueous suspension was dispersed via sonication in $8 \mathrm{~mL}$ of PBS (pH 7.4), and the resulting suspension was added to the lipid film to hydrate it for $60 \mathrm{~min}$, under continuous stirring in a water bath at $37^{\circ} \mathrm{C}$, above the main phase transition temperature (Tt) of DOTAP lipids [51], in order to prepare multilamellar vesicles (MLVs). After sufficient hydration, the suspensions were vortexed at $1500 \mathrm{rpm}$ for $10 \mathrm{~min}$. Small unilamellar vesicles (SUVs) were prepared after sonication of the resultant liposomal suspension (MLVs) for two 5 min periods interrupted by a 2 min resting period in an ice bath. The resulting SUVs were allowed to stand at room temperature for 30 min to anneal any structural defects, and then stored in a closed dark vessel at $4{ }^{\circ} \mathrm{C}$ for further use.

Empty magnetic cationic liposomes (EMCLPs) were prepared following the same experimental procedure without addition of VCur.

\subsection{Determination of $\mathrm{Fe}_{3} \mathrm{O}_{4}$ - $\mathrm{CA}$ content}

The percentage of iron incorporated into EMCLPs and VCMCLPs was estimated by FAAS. A $0.2 \mathrm{~g}$ dry sample was placed in a $100 \mathrm{~mL}$ polytetrafluoroethylene (PTFE) beaker, $20 \mathrm{~mL}$ of $6 \mathrm{~N} \mathrm{HCl}$ was added and boiled for about $1 \mathrm{~h}$ until the sample had been completely dissolved. The solution was cooled and transferred to a $200 \mathrm{~mL}$ volumetric flask. Appropriate dilution was applied if necessary and the Fe content was determined according to the standard method $3111 \mathrm{~B}$ [52] using the following calibration curve: $C_{F e}=0.027 A B S-0.015(R 2=1)$, where $C_{F e}$ stands for iron concentration in the sample (mg. $\mathrm{L}^{-1}$ ) and $A B S$ is the absorption of the sample measured at $248.3 \mathrm{~nm}$. Subsequently, the $\mathrm{Fe}_{3} \mathrm{O}_{4}-\mathrm{CA}$ content was estimated through combinatorial calculations by using the TGA data for the residual quantity of $\mathrm{Fe}_{3} \mathrm{O}_{4}$ and the weight loss caused by burning the chemisorbed CA molecules (vide infra).

\subsection{Determination of VCur entrapment efficiency and loading capacity}

The confirmation of the successful incorporation of VCur inside the liposomal matrices as depicted in Fig. 5 (vide infra) and the determination of the encapsulated percentage of VCur into VCMCLPs was estimated through HPLC analysis. A $0.02 \mathrm{~g}$ dry sample was ground and immersed in a $50 \mathrm{~mL}$ PTFE beaker, into $30 \mathrm{~mL}$ of a mixture of $\mathrm{MeOH} / \mathrm{DMSO} 2: 1(\mathrm{v} / \mathrm{v})$, and then filtered through a $0.2 \mu \mathrm{m}$ PTFE- 
membrane syringe filter. Appropriate dilution was applied for the HPLC measurements and VCur content was determined, according to the following calibration curve: CVCur $=2 \cdot 108 \times$ peak area+136,603 (R2=0.9992), where CVCur stands for VCur concentration in the sample $\left(\mathrm{mg}^{\left.-\mathrm{mL}^{-1}\right)}\right.$ and peak area is the area of the sample measured at $480 \mathrm{~nm}$.

The entrapment efficiency of VCur was calculated using the following equation: Entrapment Efficiency (\%)=VCuri/VCurt $\times 100$, where VCuri is the amount of VCur incorporated into VCMCLPs and VCurt is the initially added amount of VCur.

The loading capacity of VCur was calculated using the following equation: Loading Capacity $(\%)=$ VCuri/WVCMCLPs $\times 100$, where VCuri is the amount of VCur incorporated into VCMCLPs and WVCMCLPs is the weight of the synthesized VCMCLPs after freeze drying.

Experiments were carried out in triplicates and the results were expressed as mean \pm standard deviation (SD).

\subsection{In vitro VCur release study}

The drug release profile of VCur from VCMCLPs was performed as follows: $0.02 \mathrm{~g}$ of VCMCLP powder was ground and immersed into $30 \mathrm{~mL}$ of oxygenated (O2,100\%) PBS solution, $\mathrm{pH}$ 7.4. The temperature of the release medium was set at $37 \pm 1{ }^{\circ} \mathrm{C}$, under continuous stirring at a rate of ca. $300 \mathrm{rpm}$. Aliquots of $2 \mathrm{~mL}$ of supernatant were taken at predetermined time intervals. Following removal of insoluble solid VCMCLPs by centrifugation $(13,000 \mathrm{rpm}, 1 \mathrm{~min})$ and filtration $(0.2 \mu \mathrm{m}$ PTFE-membrane syringe filter), the remaining clear solution was analysed and the amount of VCur released was determined by HPLC, with the aid of the previous calibration curve (vide supra). Experiments were carried out in triplicates and the results were expressed as mean \pm SD.

\subsection{Circular dichroism}

Circular dichroism (CD) spectra of CT-DNA were recorded in the range $180-500 \mathrm{~nm}$ at $25^{\circ} \mathrm{C}$ on a JASCO J-715 spectropolarimeter equipped with Peltier temperature regulation system. CD spectra were acquired with four accumulations, using quartz cuvettes with $1.0 \mathrm{~cm}$ optical path length, scan speed of $100 \mathrm{~nm}$.min-1 and $1 \mathrm{~s}$ response time. Data were analyzed with the standard Jasco software package. Experiments were performed in PBS (final concentration of $2 \%$ DMSO) by keeping the DNA concentration constant $(5 \times 10-5 \mathrm{M})$ while varying the concentration of compounds $(0-2.5 \times 10-5 \mathrm{M})$ to achieve ratios $\mathrm{R}=[\mathrm{compound}] /[\mathrm{DNA}]$ of $0.0,0.01,0.05,0.1,0.2,0.33,0.5$.

\subsection{DNA melting}

DNA melting temperature measurements were performed using a Varian Cary 300 spectrophotometer equipped with a heating multiple cell block apparatus. Temperatures were maintained under computer control and were increased at a $0.5^{\circ} \mathrm{C} . \mathrm{min}-1$ rate. DNA melting experiments were carried out by monitoring the absorbance of DNA at $258 \mathrm{~nm}$ in the temperature range from $25.0^{\circ} \mathrm{C}$ to $95.0^{\circ} \mathrm{C}$. Solutions were allowed to equilibrate for $1 \mathrm{~min}$ at each temperature. Cuvettes ( $1.0 \mathrm{~cm}$ capped quartz) were mounted on a thermal block and the solution temperatures were monitored by a thermistor in the reference cuvette. The melting temperature ( $\mathrm{Tm}$ ) of DNA was determined as the midpoint of the optically detected transition and the measurement was repeated three times for each sample. The thermal melting experiments were performed in phosphate buffer solution (final concentration of $2 \%$ DMSO) by keeping the DNA concentration constant $(5 \times 10-5 \mathrm{M})$ while varying the concentration of compounds $(0-2.5 \times 10-5 \mathrm{M})$ to achieve ratios $\mathrm{R}=[$ compound $] /[\mathrm{DNA}]$ of $0,0.01,0.05,0.1,0.33,0.5$. 


\subsection{Ethidium bromide}

For competitive binding between ethidium bromide (EB, Sigma Aldrich, USA), DNA was pretreated with $E B$ in the ratio of $[D N A] /[E B]=1.3: 1$ ([DNA] $=5 \times 10-5 \mathrm{M}$ and $[E B]=3.85 \times 10-5 \mathrm{M}$ ) for $10 \mathrm{~h}$ at room temperature. The compounds $(0-1.5 \times 10-4 \mathrm{M})$ were then added to DNA-EB mixture to achieve ratios $\mathrm{R}=$ [compound]/[DNA] of $0,0.01,0.05,0.1,0.2,0.33,0.5,1,3$ and their effect on the emission intensity was measured using a Hitachi F-2500 spectrofluorimeter at $25^{\circ} \mathrm{C}$, in the wavelength range $550-700 \mathrm{~nm}$. The excitation wavelength of the samples was $520 \mathrm{~nm}$, the scan speed was 300 $\mathrm{nm}$. min-1, and both excitation and emission slit widths were $2.5 \mathrm{~nm}$. In addition, fluorescence spectra of the compounds alone, of EB alone, and of mixtures of EB with the compounds at the concentrations employed in the competitive binding studies were obtained to help in the interpretation of our results.

\subsection{Viscosity measurements}

Viscosity measurements were carried out using Ostwald's viscometer (micro-Ubbelohde, SI ANALYTICS) at $25^{\circ} \mathrm{C}$. The viscometer was thermostated at 25.0 ? $0.1^{\circ} \mathrm{C}$ in a constant temperature bath. Flow time of solutions was measured with a digital stopwatch, each sample was measured three times and an average flow time was calculated. The values did not differ by $>0.2 \mathrm{~s}$ from each other. All solutions were filtered through $1 \mu \mathrm{m}$ filters (Millipore Acrodisc) prior to the measurements. Experiments were carried out in phosphate buffer solution (final concentration of $2 \%$ DMSO) by keeping the DNA concentration constant $\left(5 \times 10^{-5} \mathrm{M}\right)$ while varying the concentration of compounds $\left(0-2.5 \times 10^{-5} \mathrm{M}\right)$ to achieve ratios $R=$ [compound] $/[\mathrm{DNA}]$ of $0,0.01,0.05,0.1,0.2,0.33,0.5$. The intrinsic viscosity [n] was calculated according to the relationship $[n]=\left(t-t_{b}\right) / t_{b}$, where $t_{b}$ is the flow time for the buffer and $t$ is the observed flow time for DNA in the presence or absence of the compounds. Data were presented as $(n / n o) 1 / 3$ versus $R$, where $n$ and $n 0$ are the intrinsic viscosities in the presence or absence of the compounds. For the low DNA concentrations used in these experiments, the intrinsic viscosity [n] is proportional to the difference in the flow times for the buffer with and without DNA, resulting in the following Eq. (2) [53].

$\frac{L}{L_{\mathrm{a}}}=\frac{[\eta]^{1 / 3}}{\left[\eta_{\mathrm{o}}\right]^{1 / 3}}=\frac{\left(t-t_{\mathrm{b}}\right)^{1 / 3}}{\left(t_{\mathrm{o}}-t_{\mathrm{b}}\right)^{1 / 3}}$

where $L$ and Lo are the DNA lengths and [ $\mathrm{n}$ ] and [no] are the intrinsic viscosities with and without the compound. The $t_{b}, t_{o}$ and $t$ are the flow times of the buffer, the plain DNA and the DNA/compound solution, respectively.

\section{Results}

\subsection{Synthesis}

$\mathrm{Fe}_{3} \mathrm{O}_{4} \mathrm{NPs}$ (core) (Scheme 1) were prepared via the co-precipitation method of ferric chloride and ferrous chloride (2:1 molar ratio) in the presence of excess ammonia solution according to a modified Massart method [54,55]. The surface of the obtained magnetite NPs was stabilized by a direct CA addition in order to obtain a ferromagnetic colloidal suspension of Fe3O4 NPs, surfacemodified with carboxylic moieties (Scheme 1). Surface functionalization with carboxylates offers the potential of achieving the required repulsive forces that can prevent agglomeration of the emerging superparamagnetic NPs and lead to the formation of a thermodynamically stable colloidal suspension (Scheme 1). 
The $\mathrm{pH}$ of the reaction during $\mathrm{Fe}_{3} \mathrm{O}_{4} \mathrm{NP}$ synthesis was high enough $(\mathrm{pH}=10.5)$ in order to prevent agglomeration due to surface charge, since the isoelectric point of $\mathrm{Fe}_{3} \mathrm{O}_{4}$ depends on $\mathrm{pH}(6 \leq \mathrm{pH} \leq 7)$, $\mathrm{Fe}^{2+}$ concentration and temperature [56,57]. Both, co-precipitation and surface modification procedures were carried out in the liquid phase, to avoid NP surface passivation, under a nitrogen atmosphere reflux at $90{ }^{\circ} \mathrm{C}$ to ensure anaerobic conditions, and under vigorous magnetic stirring for better reagent homogeneity.

$$
2 \mathrm{FeCl}_{3} \cdot 6 \mathrm{H}_{2} \mathrm{O}+\mathrm{FeCl}_{2} 4 \mathrm{H}_{2} \mathrm{O}+8 \mathrm{NH}_{3} \underset{\mathrm{pH}=10.5}{\stackrel{\mathrm{H}_{2} \mathrm{O}}{\longrightarrow}} \mathrm{Fe}_{3} \mathrm{O}_{4}+8 \mathrm{NH}_{4} \mathrm{Cl}+16 \mathrm{H}_{2} \mathrm{O}
$$

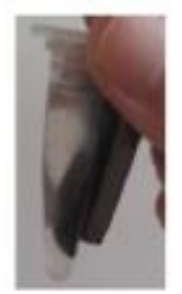

(a)

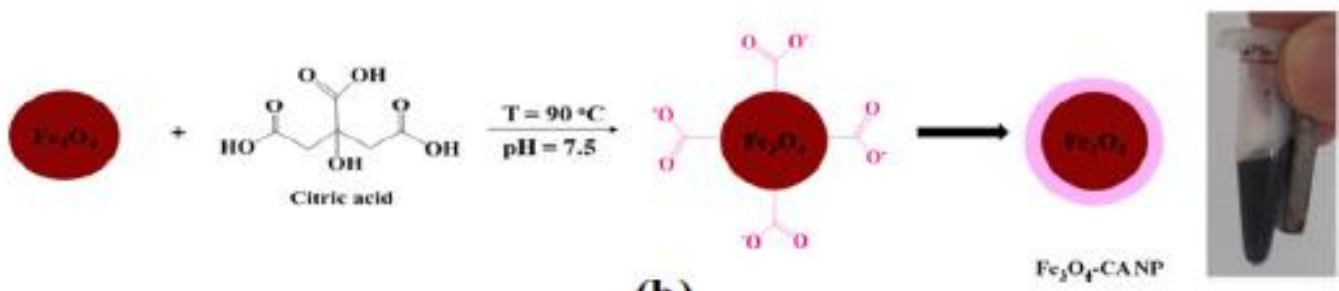

(b)

Scheme 1. a) Chemical equation leading to the synthesis of $\mathrm{Fe}_{3} \mathrm{O}_{4} \mathrm{NPs}$, and b) schematic illustration of their further functionalization to a colloidal suspension of $\mathrm{Fe}_{3} \mathrm{O}_{4}-\mathrm{CA} N \mathrm{NP}$.

During surface modification with $\mathrm{CA}$, the $\mathrm{pH}$ of the reaction was adjusted to near physiological $(\mathrm{pH}$ 7.5) as the NP stability in aqueous media is enhanced near physiological pH [58].

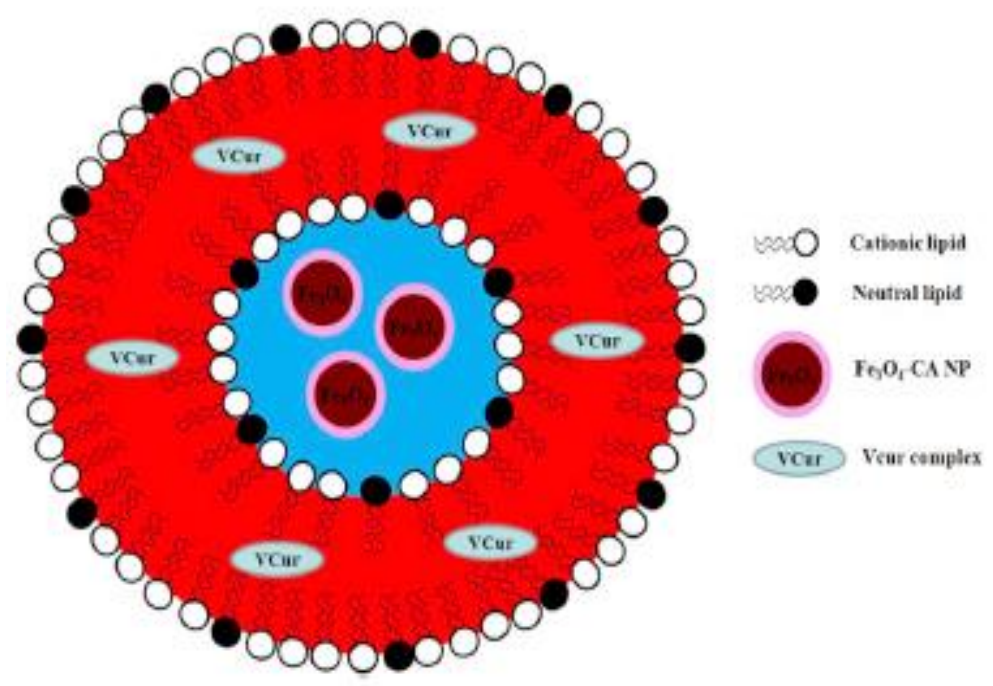

Fig. 3. Schematic illustration of a VCMCLP. The aqueous internal cavity is presented in blue color, and the lipid bilayer is presented in red color. (For interpretation of the references to color in this figure legend, the reader is referred to the web version of this article.)

The obtained $\mathrm{Fe}_{3} \mathrm{O}_{4}$-CA NPs were physicochemically characterized through a series of complementary techniques in order to: a) verify the successful CA surface modification of the magnetite NPs (FT-IR, powder XRD, XPS), b) confirm the preservation of the superparamagnetic character of the emerged ferromagnetic colloidal suspension (magnetization measurements), c) specify the size, shape, and surface charge of the CA stabilized Fe304 NPs (TEM, SEM, DLS, z- 
potential), and d) determine the thermal stability and the amount of CA absorbed on the surface of $\mathrm{Fe}_{3} \mathrm{O}_{4} \mathrm{NPs}(\mathrm{TGA})$.

VCMCLPs (Fig. 3) were prepared after initial incorporation of VCur into the emerging lipid mixture of low concentration in DOTAP and EPC and the subsequent formation of magnetic MLVs via the thin film hydration method, with the addition of a PBS colloidal suspension of $\mathrm{Fe}_{3} \mathrm{O}_{4}$-CA NPs. Subsequent sonication of the resulting MLVs led to the formation of SUVs. As presented in Fig. 3, VCur due to its hydrophobic nature is encapsulated in the bilayer membrane. The ferromagnetic colloidal suspension of Fe304-CA NPs is encapsulated in the aqueous interior of the LP. It has been reported that the utilization of both DOTAP and EPC lipids at low concentrations produces formations with broad size distributions [40]. Additionally, the combination of the corresponding lipids results in significantly high LP uptake efficiencies against cancer cells by regulating the physicochemical profile of lipid bilayers, stabilizing the liposomal structure, and optimizing LP fusion with the plasma membrane $[40,41]$. The effective liposomal encapsulation aims at enhancing VCur aqueous solubility and therefore its systemic bioavailability, circulation time, targeted delivery, and therapeutic potential (Fig. 4).
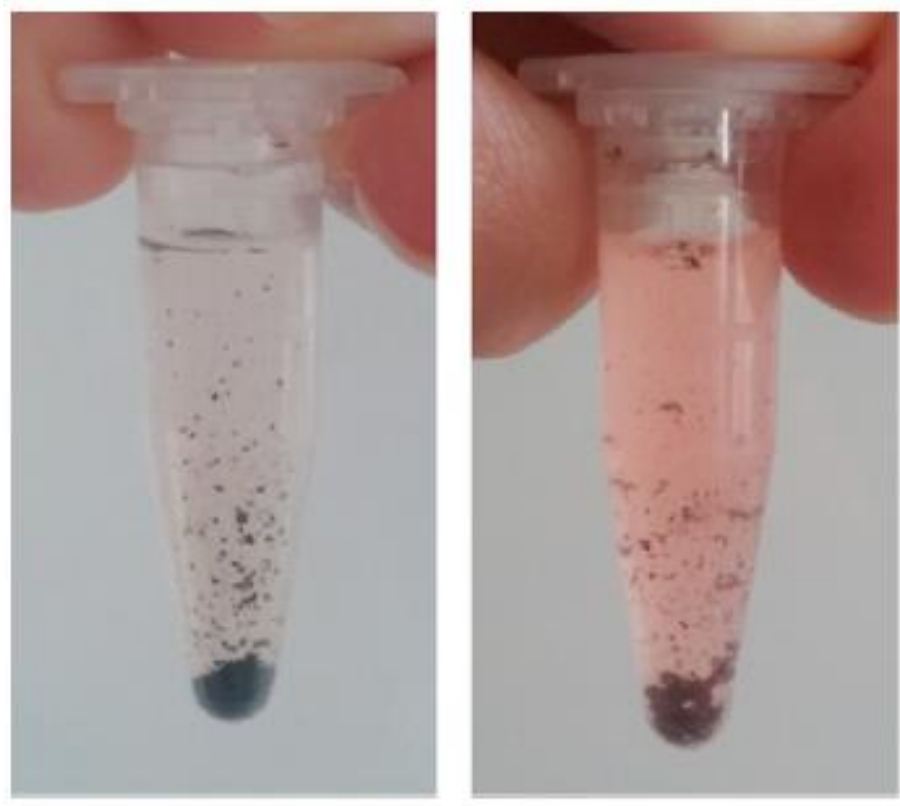

Fig. 4. VCur dispersed in $\mathrm{H} 2 \mathrm{O}$ (left), VCMCLPs dispersed in $\mathrm{H} 2 \mathrm{O}$ (right). Liposomal encapsulation of VCur enhances its solubility and thus its bioavailability.

The obtained VCMCLPs were characterized via magnetization measurements in order to define the role of LP encapsulation in the preservation of the superparamagnetic character of the encapsulated $\mathrm{Fe}_{3} \mathrm{O}_{4}-\mathrm{CA}$ NPs. TEM, SEM, DLS, and z-potential measurements were employed to further determine the morphological characteristics and the changes in the charge of the prepared liposomal formulations after the incorporation of VCur and the magnetic load in the liposomal bilayer and aqueous interior, respectively. TGA and FAAS measurements indicated the thermal stability and the amount of the encapsulated $\mathrm{Fe}_{3} \mathrm{O}_{4}$-CA NPs in the hydrophilic interior of the CLPs. Entrapment efficiency, loading capacity and release rate of VCur were determined by HPLC studies that further confirm the structural integrity of the VCur molecule during the encapsulation and release processes. 


\subsection{FT-IR spectroscopy}

The FT-IR spectra of $\mathrm{CA}$ and $\mathrm{Fe}_{3} \mathrm{O}_{4}$-CA NPs are presented in Fig. 6, and confirm the effective surface modification of magnetite NPs with CA. More specifically, in the spectrum of CA the rather broad vibration bands are indicative of the strong inter- and intramolecular hydrogen bonding. The broad absorption bands at $1728 \mathrm{~cm}-1$ and $1412 \mathrm{~cm}-1$ are assigned to the C]O antisymmetric and symmetric stretching vibrations of the $\mathrm{COOH}$ moiety, respectively. In the spectrum of $\mathrm{Fe}_{3} \mathrm{O}_{4}$-CA NPs the weak absorption band at $2919 \mathrm{~cm}-1$ is attributed to the $\mathrm{CH}_{2}$ stretching. The absorption band for the antisymmetric vibrations of the carboxylate carbonyls emerges at $1613 \mathrm{~cm}^{-1}$. Symmetric vibrations for the same group appear at $1399 \mathrm{~cm}^{-1}$. The observed carbonyl vibrations are shifted to lower frequency values in comparison to the corresponding vibrations in free $C A$, suggesting changes in the vibrational status of the citrate ligand binding to the magnetite surface by a pHsensitive chemisorption [59-62], through complexation of CA with iron, thus ascribing a partial single bond character to the $\mathrm{C}] \mathrm{O}$ bond $[63,64]$. The broad band at $562 \mathrm{~cm}-1$ can be attributed to the Fe-O stretching vibrations of $\mathrm{Fe}_{3} \mathrm{O}_{4}[65]$.

\subsection{X-ray diffraction}

The X-ray diffraction patterns of $\mathrm{Fe}_{3} \mathrm{O}_{4}-\mathrm{CA}$ NP, EMCLP and VCMCLP dried powder samples are presented in Fig. 7. The $\mathrm{Fe}_{3} \mathrm{O}_{4}$-CA NP sample (Fig. 7A) exhibits broad diffraction peaks, due to the small crystallite size, indexed as $\mathrm{Fe}_{3} \mathrm{O}_{4}$ (magnetite) according to JCPDS-ICDD Powder Diffraction File 19-0629. In EMCLP and VCMCLP samples (Fig. 7B and C) where the CA-modified magnetite NPs are encapsulated into the LPs, the peaks become very broad and only the diffraction peaks of the strongest reflections are visible above the background.

\subsection{Magnetization measurements}

From magnetization loops, the superparamagnetic character of $\mathrm{Fe}_{3} \mathrm{O}_{4}-\mathrm{CA} N \mathrm{NP}, \mathrm{EMCLP}$ and VCMCLP dried powder samples at room temperature was verified. This is expected for the particle size of the oxide core, since the critical size, $D_{s p}$, for superparamagnetism, with measuring time $100 \mathrm{~s}$, is 20-30 $m$ for iron oxide particles [66]. Superparamagnetism, the thermally activated reversal of particle magnetization, is manifested as diminishing coercivity, while magnetization remains high, and the isothermal magnetization curve obeys a Langevin function.

The blocking temperature, $T_{B}$, determined by Zero-Field-Cooled thermomagnetic measurements with a $100 \mathrm{Oe}(8 \mathrm{kA} / \mathrm{m})$ field, is $\approx 255 \mathrm{~K}$. Room temperature coercivity, shown in the insets of Fig. $8 \mathrm{~A}-$ $\mathrm{F}$, is negligible, as low as 4-5 Oe $\left(320-400 \mathrm{~A} \cdot \mathrm{m}^{-1}\right)$. At $50 \mathrm{~K}$ the thermal reversal of magnetization is blocked and a magnetic hysteresis loop is obtained for all three samples, with a coercivity of 145160 Oe (11.6-12.8 kA.m-1). The specific magnetization of the iron oxide core in $\mathrm{Fe}_{3} \mathrm{O}_{4}$-CA NPs at the maximum field ( $3 \mathrm{~T}$ ) at room temperature is $65.9 \mathrm{emu}^{-1} \mathrm{~g}^{-1}$, a value corresponding to $80 \%$ of the magnetization of bulk magnetite. A wide range of magnetization values, lower than the bulk ones, are reported for iron oxide NPs [67]. Magnetite (Fe3O4), with an inverse spinel ferrite structure, has a magnetic moment of $4 \mu \mathrm{B}$ per f.u., which gives a theoretical value of specific saturation magnetization Ms $96 \mathrm{emu}^{-1} \mathrm{~g}^{-1}\left(\mathrm{Am}^{2} \cdot \mathrm{kg}^{-1}\right)$ at $0 \mathrm{~K}$. Magnetite oxidizes to maghemite $\left(\nu-\mathrm{FeO}_{3}\right)$, an iron deficient spinel with lower magnetization [68]. At the surface of magnetite particles, a thin maghemite shell may form, thus reducing NP magnetization [69]. Due to the high surface area to volume ratio of NPs, magnetization is strongly dependent on size and diminishes with decreasing size, since the magnetic moments of surface atoms are not aligned to those of the core. Besides surface spin disorder [70], the additional mass of the non-magnetic CA capping layer reduces magnetization, while LP encapsulation also affects magnetization [71]. 


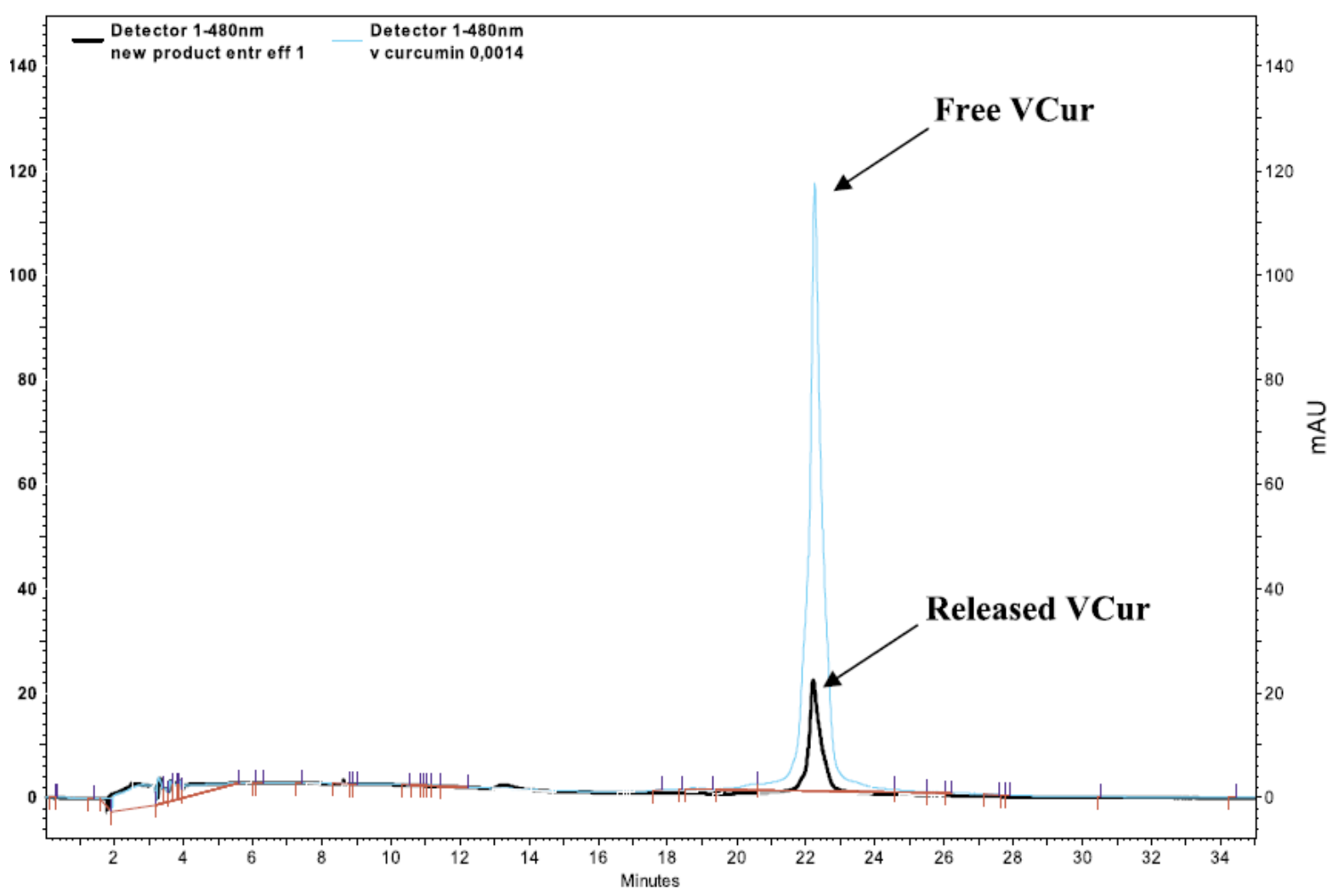

Fig. 5. HPLC spectrum of free VCur (light blue line) and released VCur (black line). (For interpretation of the references to color in this figure legend, the reader is referred to the web version of this article.)

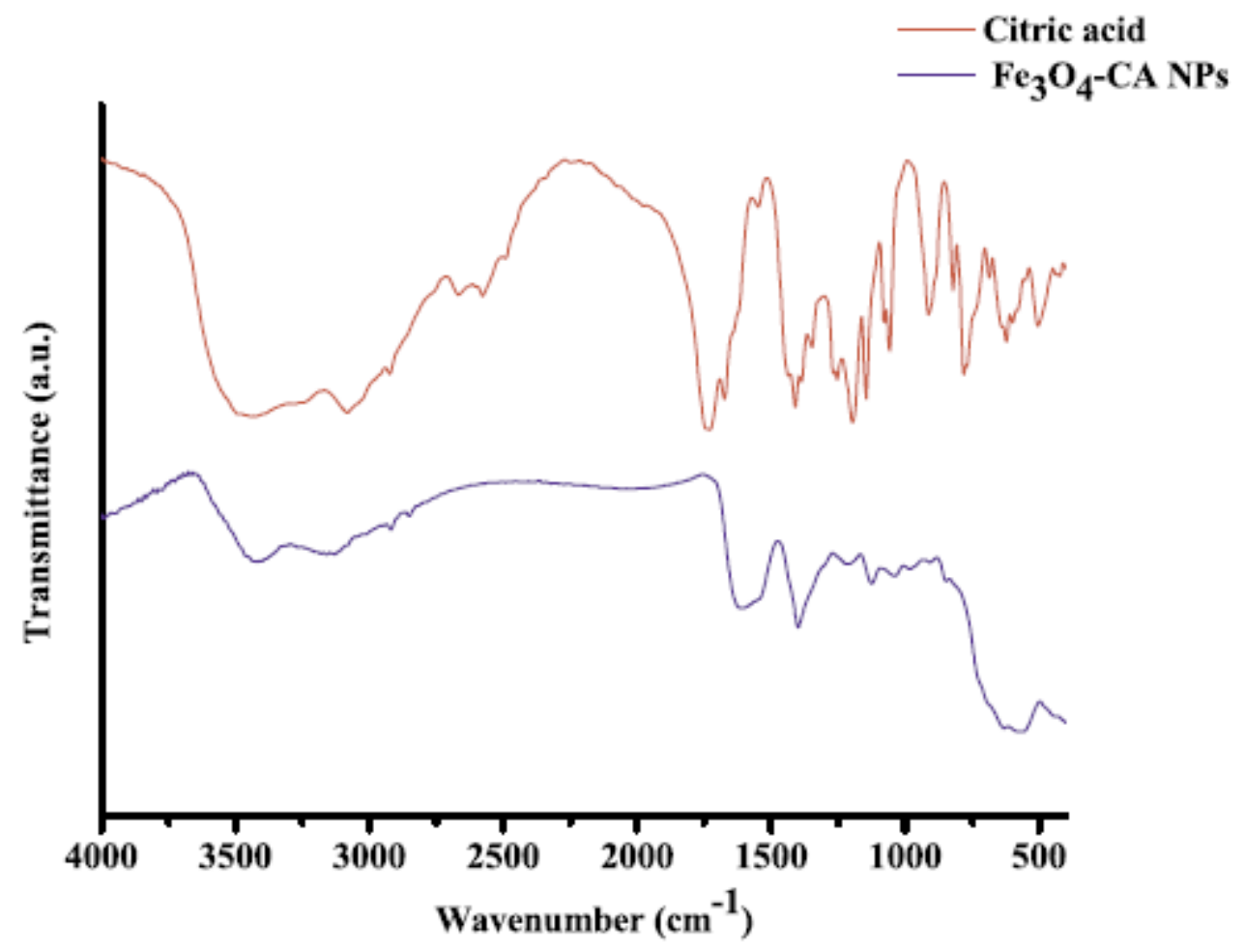

Fig. 6. FT-IR spectra of CA and Fe3O4-CA NPs. 

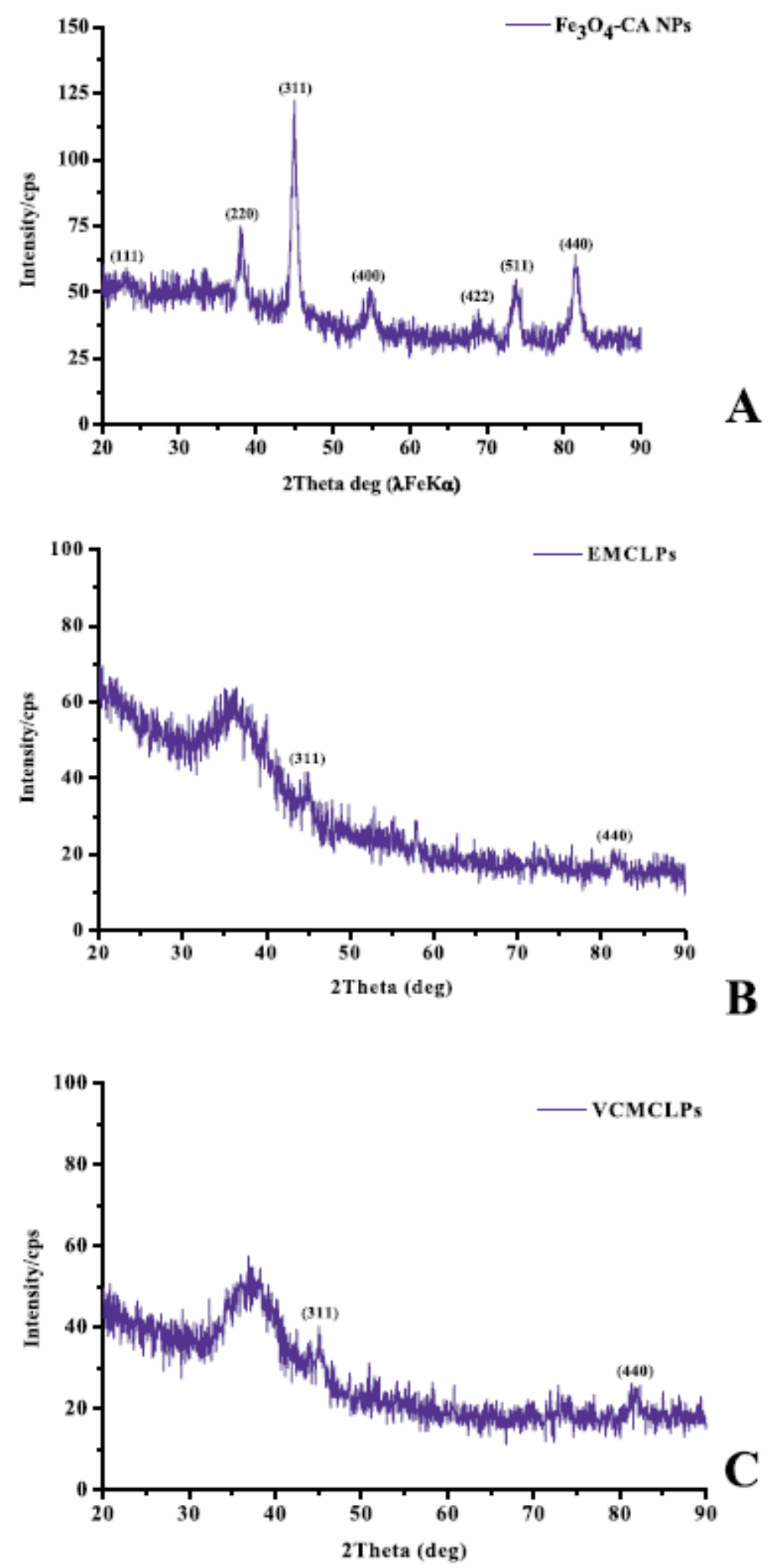

Fig. 7. A) XRD pattern of $\left.\mathrm{Fe}_{3} \mathrm{O}_{4}-\mathrm{CA} N \mathrm{NS}, \mathrm{B}\right) \mathrm{XRD}$ pattern of EMCLPs, C) XRD pattern of VCMCLPs. 

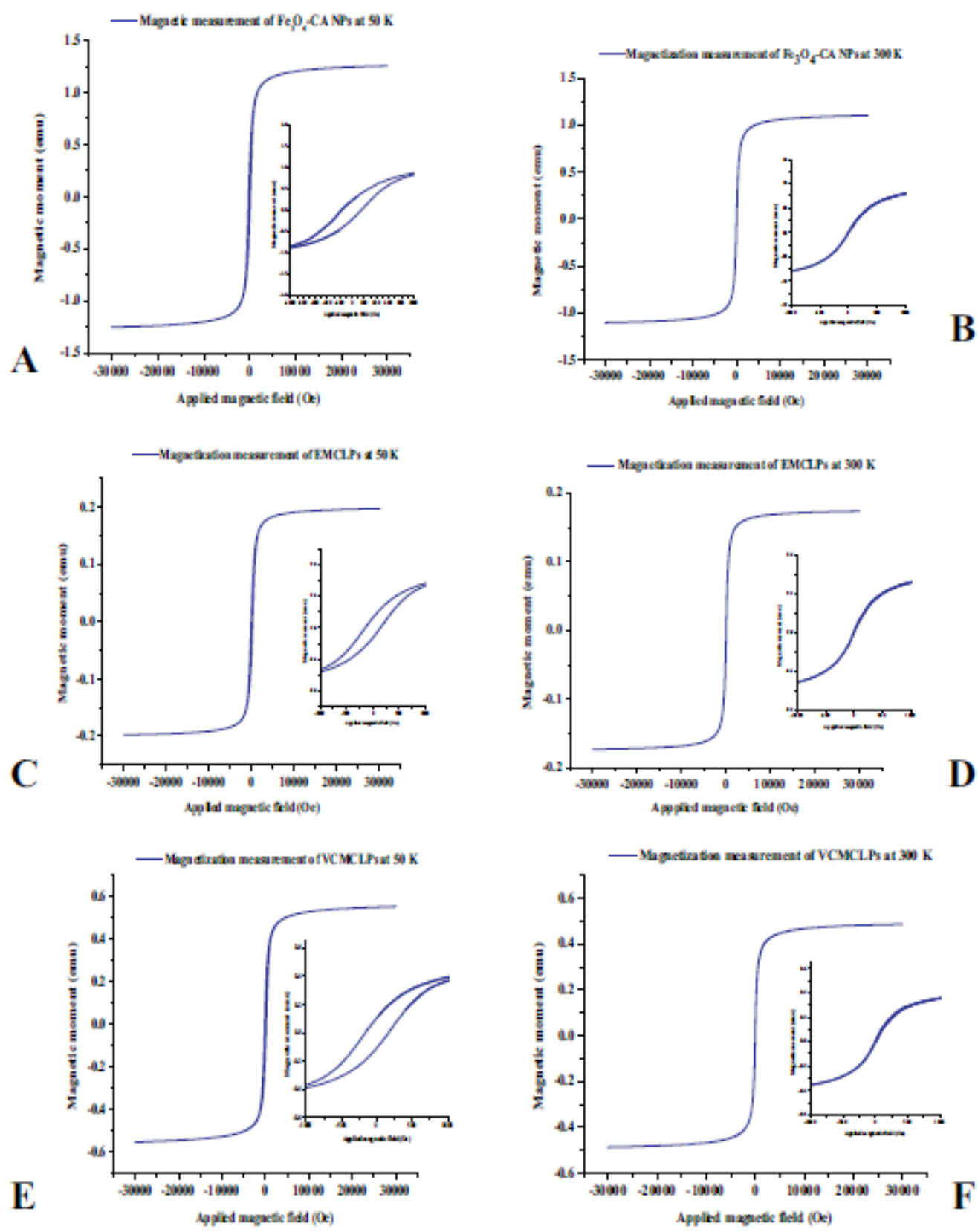

Fig. 8. Magnetization measurements of: A) Fe3O4-CA NPs at $50 \mathrm{~K}$ and B) $300 \mathrm{~K}, \mathrm{C})$ EMCLPs at $50 \mathrm{~K}$ and D) $300 \mathrm{~K}, \mathrm{E}) \mathrm{VCMCLPs}$ at $50 \mathrm{~K}$ and F) $300 \mathrm{~K}$. The magnetic field range in the inset graph is -1000 to +1000 Oe.

\subsection{XPS analysis}

The XPS spectrum of prepared films of Fe304-CA NPs on Si is shown in Fig. 9A. The spectrum shows strong $\mathrm{C} 1 \mathrm{~s}$ and $\mathrm{O} 1 \mathrm{~s}$ peaks, along with Fe $2 \mathrm{p}, \mathrm{Si} 2 \mathrm{p}$, and weak signals from $\mathrm{N} 1 \mathrm{~s}, \mathrm{~K} 2 \mathrm{~s}, \mathrm{Cl} 2 \mathrm{p}$ and $\mathrm{P} 2 \mathrm{p}$. The $\mathrm{K}, \mathrm{Na}, \mathrm{Cl}$ and $\mathrm{P}$ peaks originate from the phosphate saline buffer, and the $\mathrm{Si}$ is from exposed areas of the underlying substrate. Higher resolution scans over the Fe $2 p, C$ s and $O 1 s$ peaks are shown in Fig. 9B, $C$, and $D$, respectively. The Fe $2 p$ spectrum shows the expected $2 p_{3 / 2}-2 p_{1 / 2}$ doublet, with a separation of approximately $13 \mathrm{eV}$ and a $2 \mathrm{p}_{3 / 2}$ binding energy of approximately $711.0 \mathrm{eV}$ typical of $\mathrm{Fe}_{3} \mathrm{O}_{4}$. The asymmetry of the peaks and presence of shake-up intensity on the high binding energy side of the peak confirm this identification. The $C 1$ s peak shows a main component at 285.0 $\mathrm{eV}$ due to carbon in C-C bonds, with weaker components at approximately $286.8 \mathrm{eV}$ due to carbon in $\mathrm{C}-\mathrm{O}$ bonds and $288.9 \mathrm{eV}$ due to carbon in $\mathrm{COO}^{-}$acid groups. These chemical groups are consistent 
with the presence of CA. This is in agreement with the form of the 01 s peak shown in Fig. 9D. The main component at $532.2 \mathrm{eV}$ is attributed to oxygen bound to carbon in an organic group consistent with the presence of $\mathrm{C}-\mathrm{O}$ or $\mathrm{COO}^{-}$bonds, not separately resolvable. The lower binding energy component at $530.1 \mathrm{eV}$ is indicative of $\mathrm{Fe}_{3} \mathrm{O}_{4}$, and the weaker component at approximately $534.4 \mathrm{eV}$ is a weak X-ray excited KVV Auger peak from the low level of Na present on the sample.
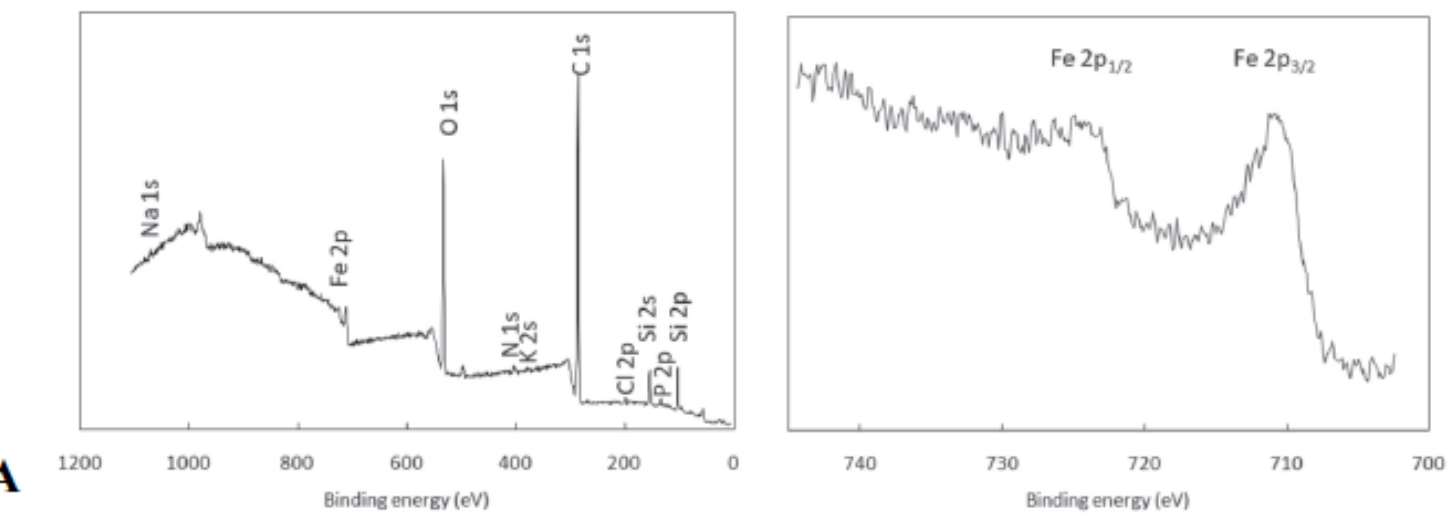

B
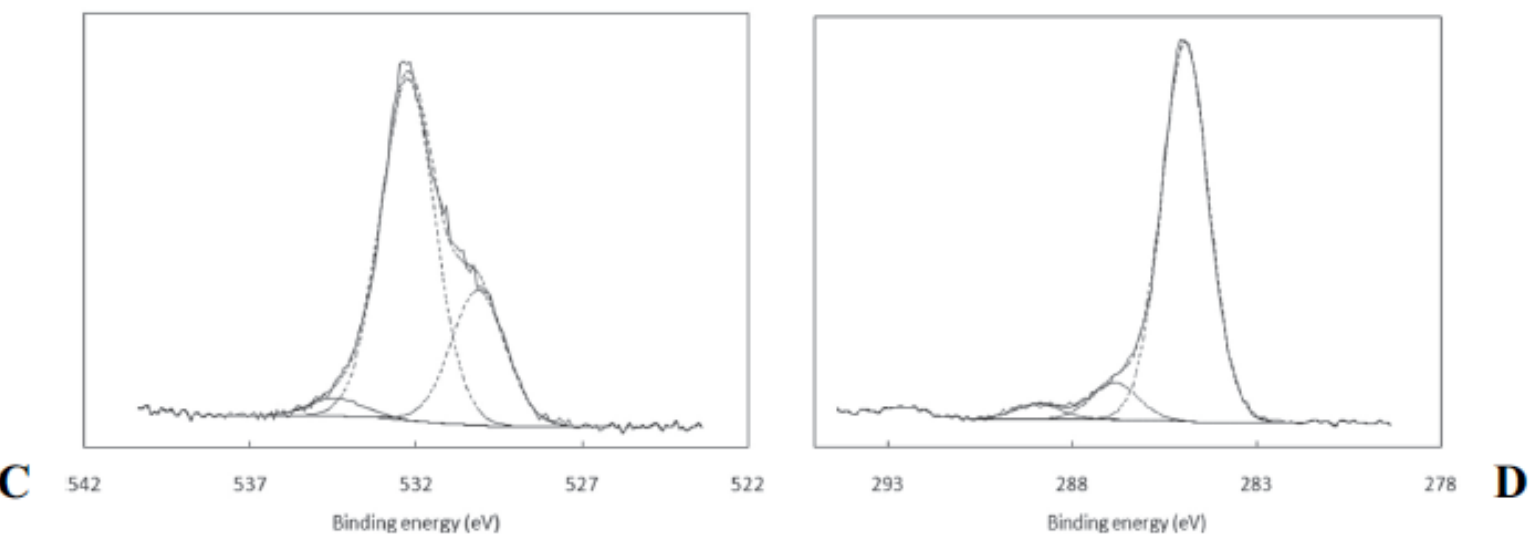

Fig. 9. XPS spectra of Fe3O4-CA NPs: A) survey, B) Fe 2p, C) O 1s, D) C 1s.

\subsection{TEM analysis}

The diameters of $\mathrm{Fe}_{3} \mathrm{O}_{4}$-CA NPs and VCMCLPs were determined by TEM as presented in Fig. 10A-D. TEM observations confirmed that $\mathrm{Fe}_{3} \mathrm{O}_{4}$-CA NPs exhibit uniform spherical morphology and relatively narrow size distribution with an average particle size around $16 \pm 5 \mathrm{~nm}$. The fractal structure of the depicted $\mathrm{Fe}_{3} \mathrm{O}_{4}$-CA NP aggregates implies gelation and chain-formation process of individual NPs to submicron clusters, thus denoting the agglomeration tendency of the emerged MNPs [72-74]. The consecutive centrifugations throughout the synthetic procedure, the application of an external magnetic field due to the magnetic agitation during the ferromagnetic phase of stabilization with CA, and the subsequent drying process that precedes TEM measurements may account for the increased tendency towards agglomeration [61]. TEM images of the VCMCLP sample indicate the presence of predominantly distinct liposomal nano-formulations with spherical morphology and an average size between 70-120 nm, and the existence of scattered agglomerates with no specific shape and size. The observed mean diameter of the spherical NPs is typical of the utilization of cationic lipids in the synthetic procedure [75], and representative of the SUV mean diameter range [76]. 

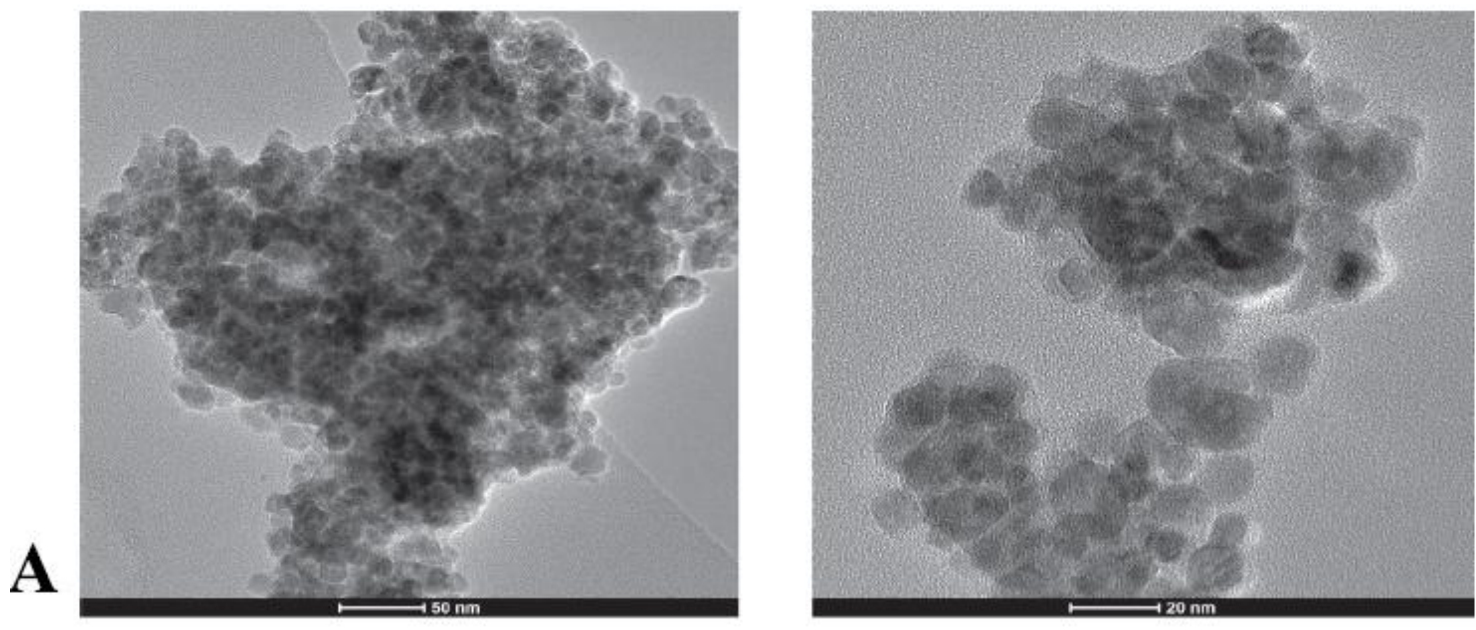

B
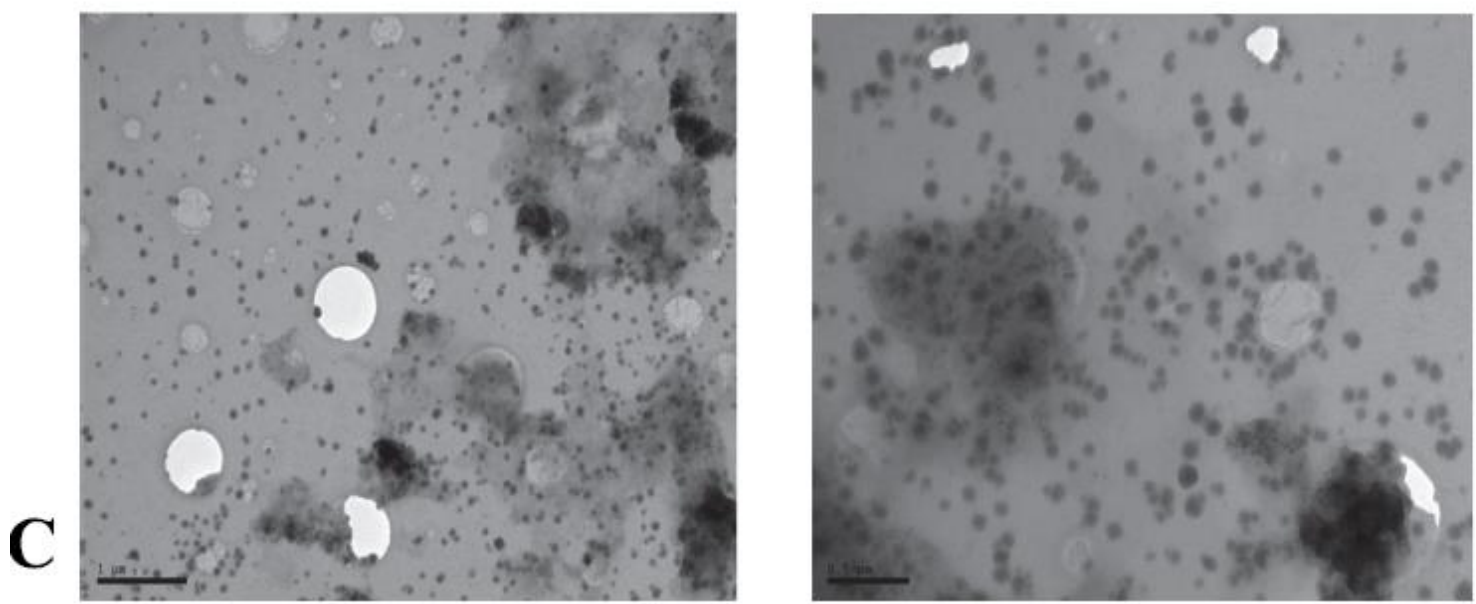

D

Fig. 10. TEM images of: A) Fe3O4-CA NPs at $50 \mathrm{~nm}$ and B) $20 \mathrm{~nm}, \mathrm{C}$ ) VCMCLPs at $1 \mu \mathrm{m}$ and D) $0.5 \mu \mathrm{m}$.

\subsection{DLS and z-potential}

For comparative purposes, DLS was employed to further determine the particle size of $\mathrm{Fe}_{3} \mathrm{O}_{4}-\mathrm{CA} \mathrm{NP}$, EMCLP and VCMCLP samples as presented in Fig. 11A-C. It is well documented that utilization of MNPs can significantly affect the size and charge of the emerging liposomal nanocarriers $[77,78]$. As a result, the amount of the incorporated magnetic load into the liposomal interior should be efficiently controlled in order to develop liposomal formulations a) with maintained size and charge, and b) sufficiently responsive to an applied external magnetic field. Furthermore, changes in LP dispersity index and size provide useful information on the modifications of the liposomal bilayer. The results at hand show that the mean hydrodynamic size of $\mathrm{Fe}_{3} \mathrm{O}_{4}$-CA NPs is $87 \pm 1.4 \mathrm{~nm}$ with a stable polydispersity index $(\mathrm{PI}) \sigma_{\mathrm{Pl}}=0.224 \pm 0.014$, thus indicating the presence of large clusters as a result of agglomeration promoted by the high concentration of magnetic NPs in the buffer solution. The characteristic stability of $\mathrm{Fe}_{3} \mathrm{O}_{4}-\mathrm{CANP}$ polydispersion is mainly due to the robust coating formed on the magnetite surface by the coordinated to iron carboxylate groups of CA and the presence of uncoordinated carboxylates of $C A$ in direct contact with the aqueous medium $[73,79,80]$. The mean hydrodynamic size of EMCLPs is $109 \pm 10.3 \mathrm{~nm}$, with $\mathrm{PI} \sigma_{\mathrm{PI}}=0.272 \pm 0.024$, indicating the presence of scattered agglomerates in the buffer solution. In the case of VCMCLPs, the mean hydrodynamic size is $181 \pm 18.1 \mathrm{~nm}$, with PI $\sigma_{\mathrm{PI}}=0.286 \pm 0.036$, also implying the presence of scattered aggregates in the buffer solution. The observed difference between the size of VCMCLPs and that of EMCLPs can be attributed to the VCur load. 
Zeta-potential measurements were conducted immediately after determination of particle size. It has been observed that CA-surface modification of magnetite NPs results in highly negative surface charged $\mathrm{Fe}_{3} \mathrm{O}_{4}$-CA NPs $(-29.75 \pm 5.45 \mathrm{mV}$ at $\mathrm{pH} 7.4)$, due to the presence of negatively charged CA carboxylates on the surface of magnetite NPs $[60,81]$. Zeta-potential for EMCLPs was measured to be $32.7 \pm 6.32 \mathrm{mV}$. The observed decrease of zeta-potential for the EMCLP sample compared to literature reported zeta-potential values of CLPs [41] indicates partial neutralization by addition of the negatively charged $\mathrm{Fe}_{3} \mathrm{O}_{4}$-CA NPs. In the case of VCMCLPs, the zeta-potential was measured to be $38.3 \pm 8.23 \mathrm{mV}$. This increase of zeta-potential compared to the EMCLP sample can be attributed to alterations of the structural integrity of the LP bilayer induced by the encapsulation of VCur $[82,83]$, and the positive charge of the encapsulated VCur species [VO(C21H19O6)(C1OH8N2)]+ [36].
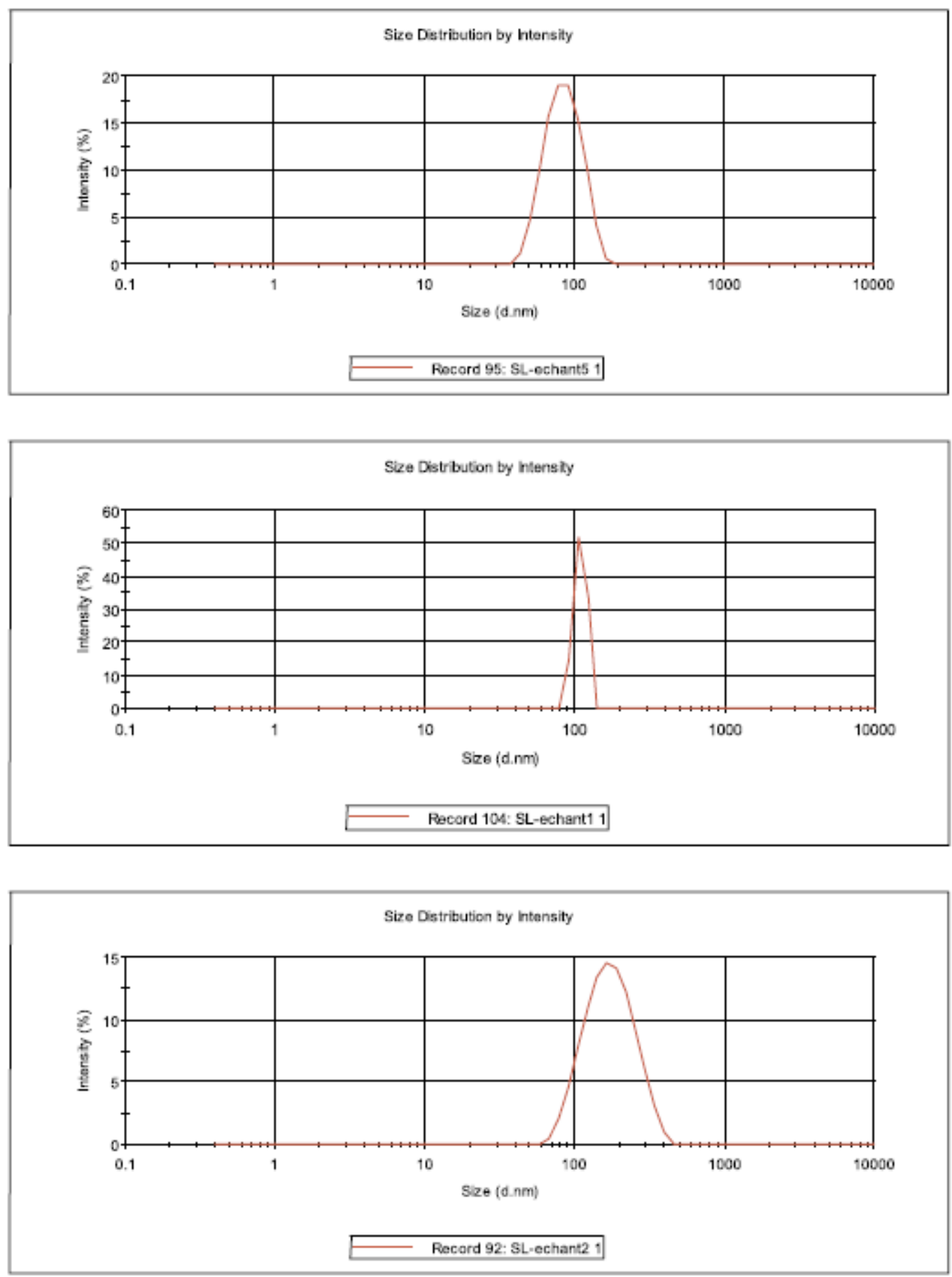

Fig. 11. Particle size distribution of: A) Fe3O4-CA NPs, B) EMCLPs, and C) VCMCLPs. 


\subsection{SEM analysis}

The morphologies of all samples were examined by SEM. Fig. 12 presents SEM images of the morphology of $\mathrm{Fe}_{3} \mathrm{O}_{4}$-CA NPs (Fig. 12A-B), EMCLPs (Fig. 12C-D), and VCMCLPs (Fig. 12E-F), respectively. The $\mathrm{Fe}_{3} \mathrm{O}_{4}-\mathrm{CA} N \mathrm{NP}$ sample projects large, dense aggregates of agglomerated uniform spherical NPs, with a relatively narrow size distribution. SEM images of the EMCLP and VCMCLP samples indicate a fluffy arrangement of the densely agglomerated spherical powder particles that form micron-sized aggregates of no specific shape and structure. This is mainly due to the lyophilization process that promotes fusion of the phospholipid membranes of the CLPS and the ensuing creation of an amorphous lipid cake, eliminating the distinctiveness of the liposomal vesicles $[84,85]$.

\subsection{Thermal studies}

The thermal decomposition of $\mathrm{Fe}_{3} \mathrm{O}_{4}-\mathrm{CA}$ NPs, EMCLPs, and VCMCLPs was studied by TGA under an atmosphere of air (Fig. 13). The $\mathrm{Fe}_{3} \mathrm{O}_{4}$-CA NPs sample was stable up to $30^{\circ} \mathrm{C}$. The observed weight loss of about $7.1 \%$ between $30^{\circ} \mathrm{C}$ and $130^{\circ} \mathrm{C}$ could be attributed to the removal of the physisorbed $\mathrm{CA}$ and water molecules. Further weight loss of about $12.9 \%$, between $130^{\circ} \mathrm{C}$ and $524{ }^{\circ} \mathrm{C}$, pointed to the decomposition of the chemisorbed $\mathrm{CA}$ molecules. A negligible weight loss of about $1.5 \%$ beyond $520{ }^{\circ} \mathrm{C}$ was due to the $\mathrm{Fe}_{3} \mathrm{O}_{4}-\mathrm{Fe}_{2} \mathrm{O}_{3}$ phase transformation [60]. The EMCLP sample was stable up to $30{ }^{\circ} \mathrm{C}$. The observed weight loss of about $26.4 \%$, between $30^{\circ} \mathrm{C}$ and $185^{\circ} \mathrm{C}$, was due to the loss of the physisorbed water and CA molecules. At higher temperatures, between $185^{\circ} \mathrm{C}$ and $526^{\circ} \mathrm{C}$, burning of the organic structure of the LPs and the chemisorbed CA molecules also contributed to a further weight loss of about $22.5 \%$. Further weight loss of about $7 \%$, beyond $526^{\circ} \mathrm{C}$, could be attributed to the aforementioned $\mathrm{Fe}_{3} \mathrm{O}_{4}-\mathrm{Fe}_{2} \mathrm{O}_{3}$ phase transformation.

The VCMCLP sample was stable up to $30^{\circ} \mathrm{C}$. The observed weight loss of about $10.8 \%$, between 30 ${ }^{\circ} \mathrm{C}$ and $170^{\circ} \mathrm{C}$, was due to the loss of the physisorbed water and CA molecules. At higher temperatures, between $170{ }^{\circ} \mathrm{C}$ and $493^{\circ} \mathrm{C}$, further weight loss of $37.1 \%$ was attributed to the burning of the organic structure of the LPs, the encapsulated VCur molecule, and the chemisorbed CA molecules. Further weight loss of about $6.3 \%$, beyond $493^{\circ} \mathrm{C}$, could be attributed to the $\mathrm{Fe}_{3} \mathrm{O}_{4^{-}}$ $\mathrm{Fe}_{2} \mathrm{O}_{3}$ phase transformation. The violent reaction observed beyond $680^{\circ} \mathrm{C}$ could be related to changes of the crystalline structure of the encapsulated VCur molecule as also observed in our previous experimental work [36]. The described tentative assignments were consistent with previously reported results of thermogravimetric analysis [86].

\subsection{0. $\mathrm{Fe}_{3} \mathrm{O}_{4}-\mathrm{CA}$ content}

The in situ $\mathrm{Fe}_{3} \mathrm{O}_{4}$-CA NP loading efficiency for the EMCLP and VCMCLP samples was determined through FAAS and TGA and estimated to be $121 \mathrm{mg} \mathrm{Fe} \mathrm{O}_{4}$-CA NPs per $1 \mathrm{~g}$ of EMCLPs and $141 \mathrm{mg}$ $\mathrm{Fe}_{3} \mathrm{O}_{4}$-CA NPs per $1 \mathrm{~g}$ of $\mathrm{VCMCLPS}$.

\subsection{VCur entrapment efficiency and loading capacity}

The in situ entrapment efficiency and loading capacity of VCur in VCMCLPs was estimated to be $38 \%$ and $9.5 \%$, respectively. The observed relatively low encapsulation efficiency and loading capacity are probably due to: a) the bulk structure of VCur complex that limits sufficient entrapment inside the bilayer membrane of the emerged LPs, b) the repulsive forces caused by the positive charge of the VCur complex and the cationic liposomal vesicles, c) the utilization of EPC in the synthetic procedure of the specific LPs that leads to the formation of liposomal formulations with reduced entrapment efficiency, as also observed in other literature reports [82], and d) the selected low lipid-to-complex 
ratio that was employed during the preparation of the VCMCLPs that consequently leads to lower entrapped drug [87].
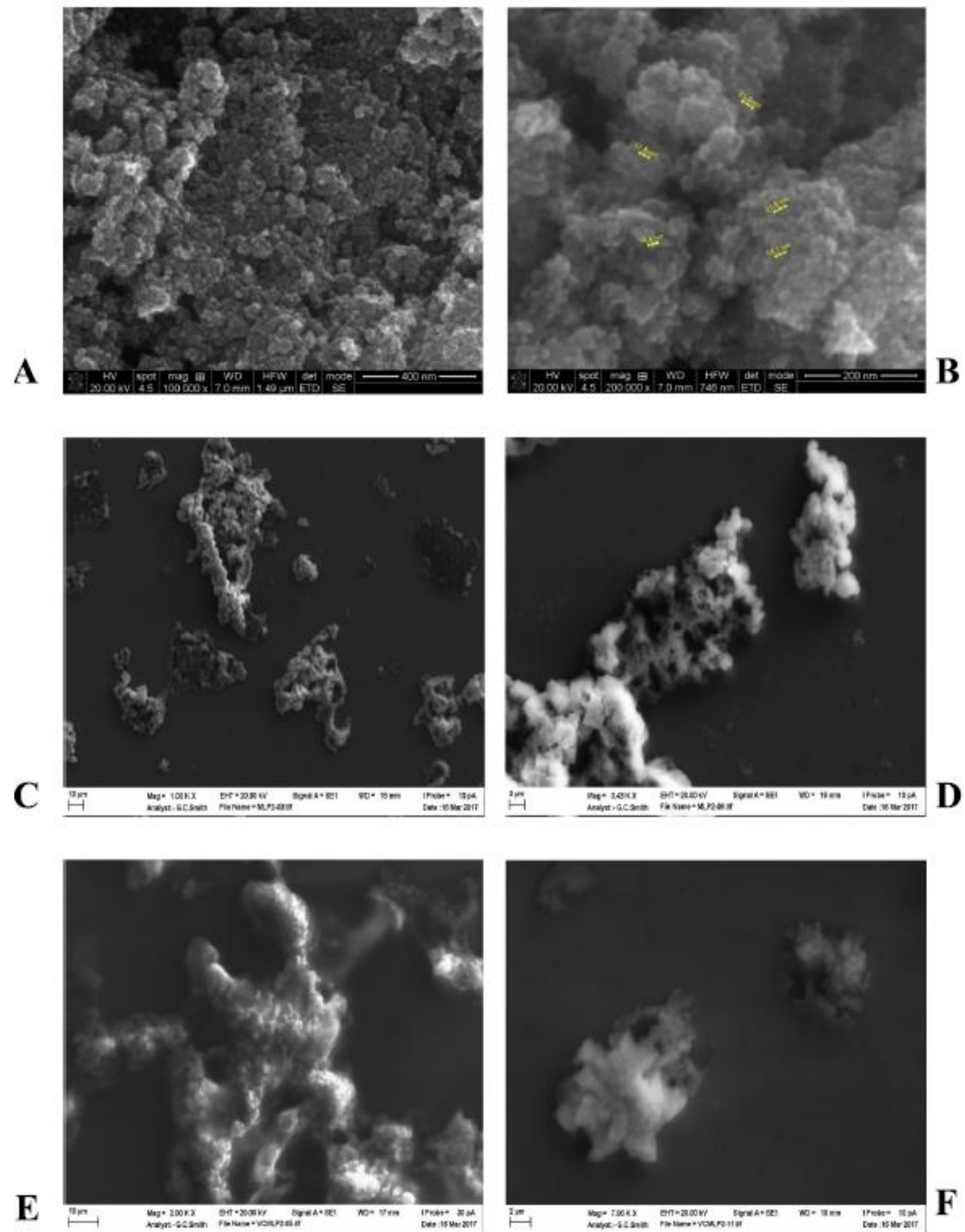

Fig. 12. SEM images of: A) $\mathrm{Fe}_{3} \mathrm{O}_{4}-\mathrm{CA} N \mathrm{Ns}$ at $400 \mathrm{~nm}$ and B) $\left.200 \mathrm{~nm}, \mathrm{C}\right) \mathrm{EMCLPs}$ at $10 \mu \mathrm{m}$ and D) $3 \mu \mathrm{m}$, E) VCMCLPs at $10 \mu \mathrm{m}$ and F) $2 \mu \mathrm{m}$. 


\subsection{In vitro VCur release study}

The release profile of the active ingredient (VCur) is an important factor for the modulation of the VCMCLP pharmacokinetic behavior. The evaluation criteria of the release profile should include: the total amount of VCur released and release rate. Fig. 14 shows the percentage of VCur released with regard to the total entrapped VCur versus time. The equilibrium release percentage of VCur from VCMCLPs was estimated to be around $10.53 \%$. A closer examination of the release profile during 48 $\mathrm{h}$ of study shows that the drug release rate was high up to about $12 \mathrm{~h}$, then the process got slower and the rate significantly decreased. The low release percentage of VCur can be attributed to its hydrophobic nature and its facile accommodation into the hydrophobic environment of the liposomal bilayer, a region where contact with aqueous media is limited [41]. Furthermore, the positive charge on the surface of the liposomes may exert an electrostatic repulsive effect on VCur, hindering its passage through the lipid layer and release in the outer medium.

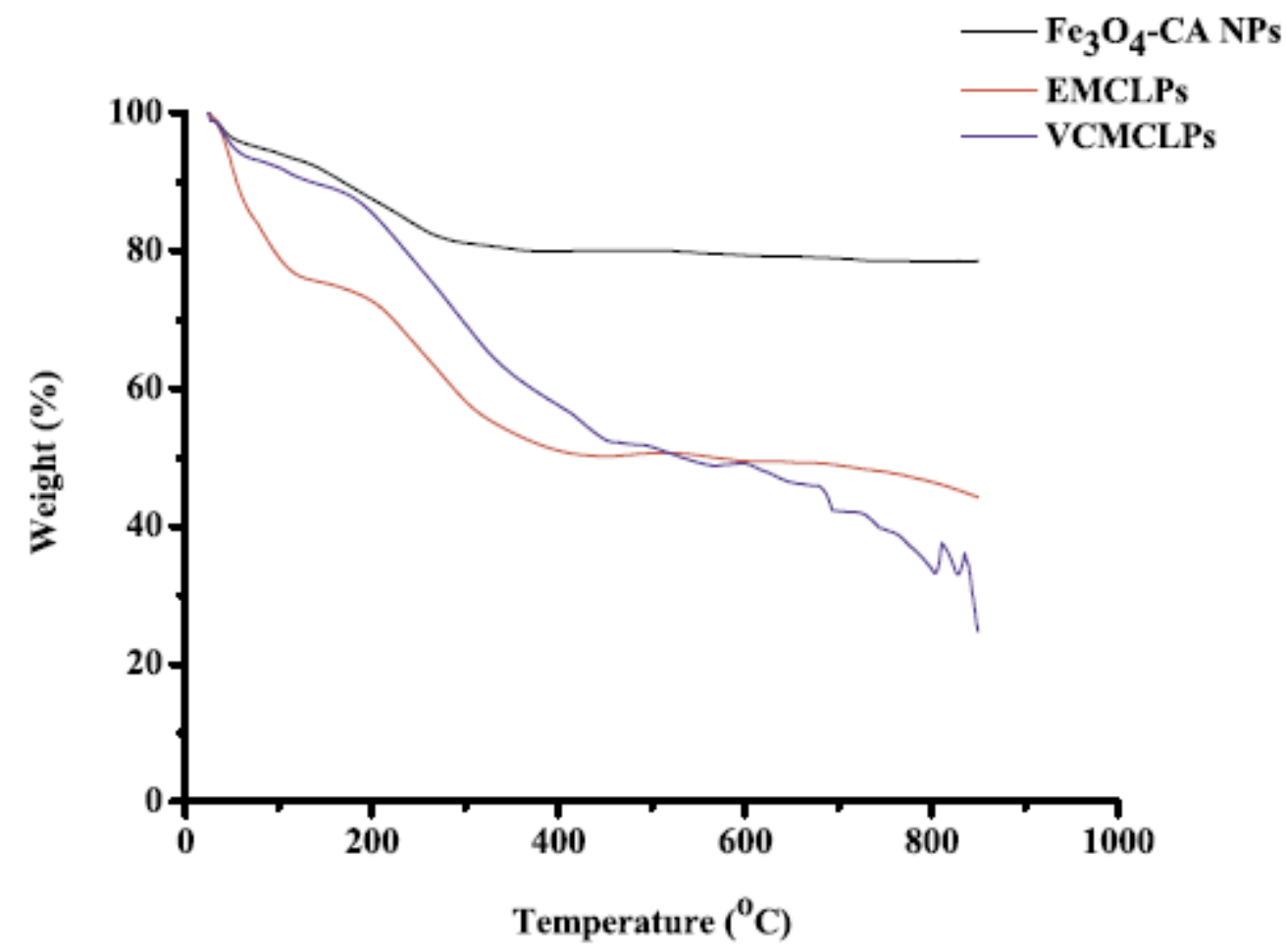

Fig. 13. TGA diagrams of: Fe3O4-CA NPs (black line), EMCLPs (red line), VCMCLPs (blue line). (For interpretation of the references to color in this figure legend, the reader is referred to the web version of this article.)

\subsection{Circular dichroism studies}

Circular dichroism (CD) is a spectroscopic technique widely used to study the structure and interactions of biomolecules, like DNA [88]. The spectrum of CT-DNA in its typical B-form consists of a positive band one at $275 \mathrm{~nm}$, due to base-stacking and a negative one at $245 \mathrm{~nm}$ due to righthanded helicity [89]. The effect of the VCur complex on the native structure of DNA was studied first to serve as reference for the evaluation of the interaction of the VCur-loaded magnetic cationic liposomes (VCMLPs). CD spectra of CT-DNA were recorded at increasing [VCur]/[DNA] ratios ( $R=0$, $0.01,0.05,0.1,0.2,0.33,0.5)$ and are shown in Fig. 15A. It is obvious that no major changes are observed in the CD spectra of DNA with the exception of a bathochromic shift of the positive band by $2 \mathrm{~nm}$ and of the negative band by $1 \mathrm{~nm}$. As can be seen in Fig. 15B, upon addition of VCMLPs changes are observed in both positive and negative bands of CT-DNA. In particular, the intensity of 
positive band is increased in a dose-dependent way, reaching at the highest ratio of $\mathrm{R}=0.5$ an increase of $40 \%$ relative to its initial height. The intensity of the negative band initially decreases in intensity and subsequently increases, at the higher VCMLP concentrations. A gradual bathochromic shift of the negative band approx. $3 \mathrm{~nm}$ and of the positive band by $2 \mathrm{~nm}$ is also recorded upon increasing VCMLP concentration. No induced CD was generated and at all ratios, furthermore, both negative and positive bands are present indicating that CT-DNA retains the basic B-form characteristics. It should also be noted that no changes were observed in the CD spectra of DNA upon addition of $\mathrm{Fe}_{3} \mathrm{O}_{4}$-CA NPs and EMCLPs, that served as control.

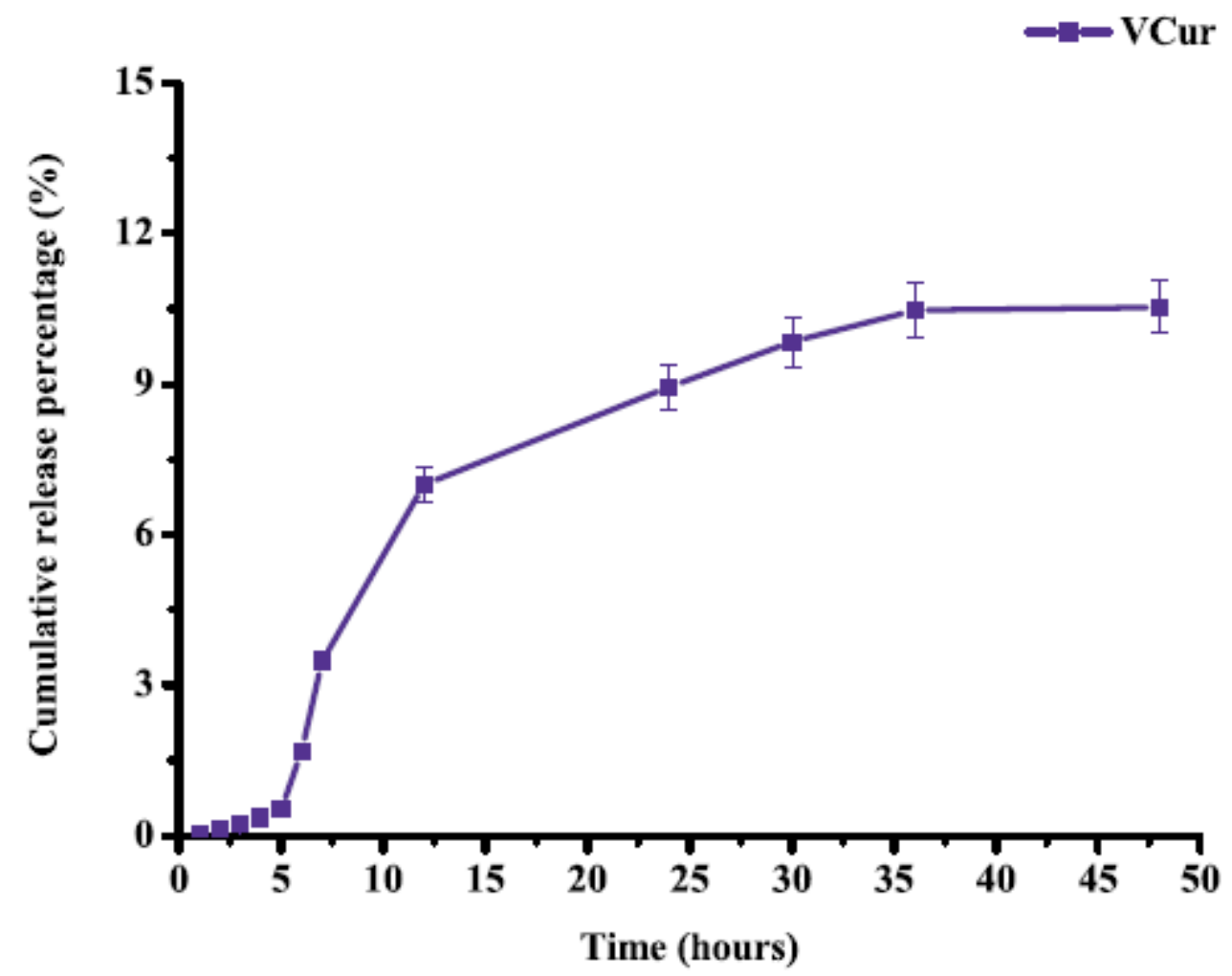

Fig. 14. Cumulative release percentage of VCur with regard to the total entrapped VCur vs. time. 

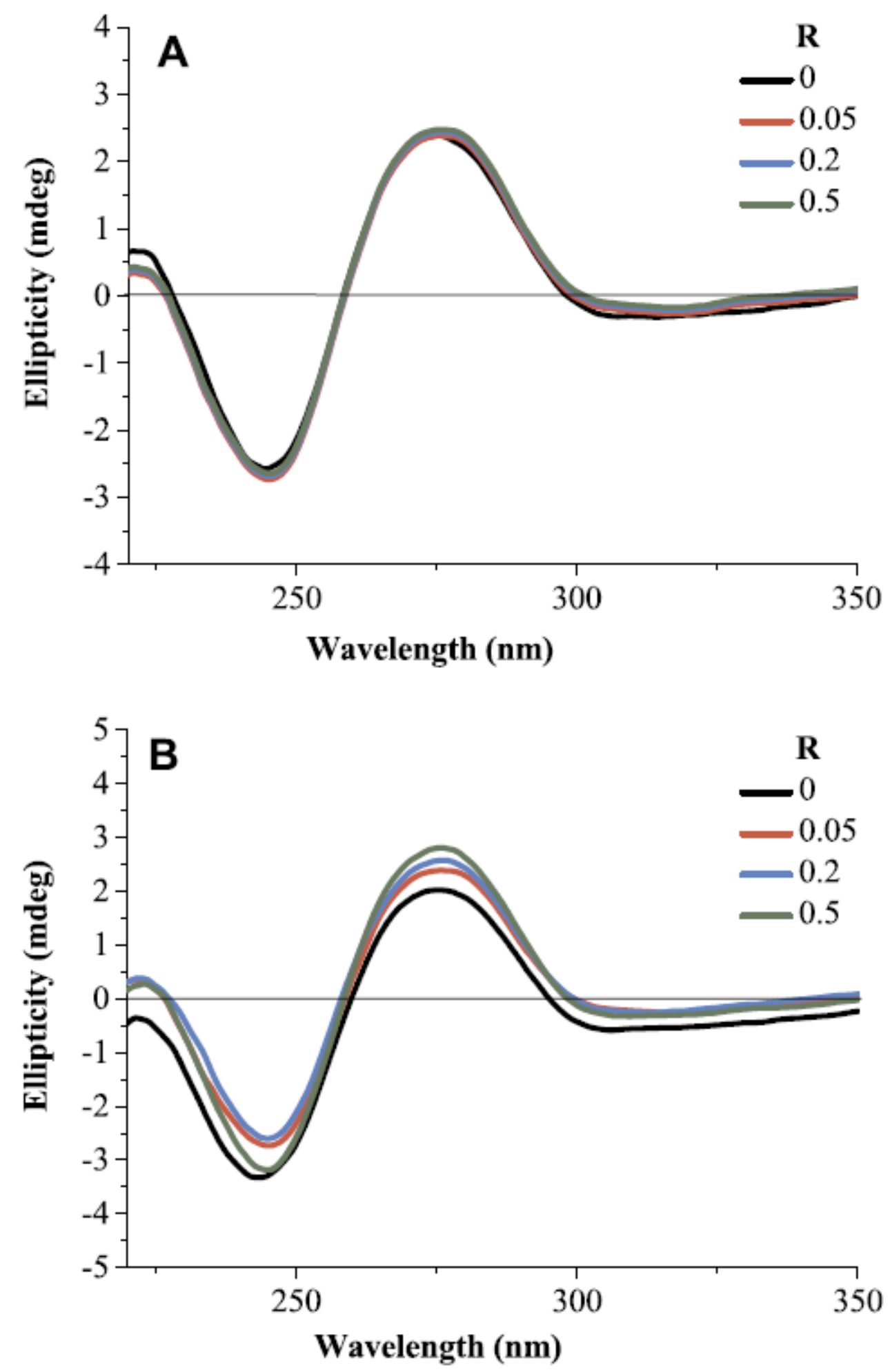

Fig. 15. Circular dichroism spectra of DNA $(5 \times 10-5 \mathrm{M})$ with increasing amounts of $A)$ VCur and $B)$ VCMCLPs. The ratios $\mathrm{R}=[$ compound]/[DNA] employed ranged from 0 to 0.5 . For clarity, the spectra from only four Rs are presented in the figure. 


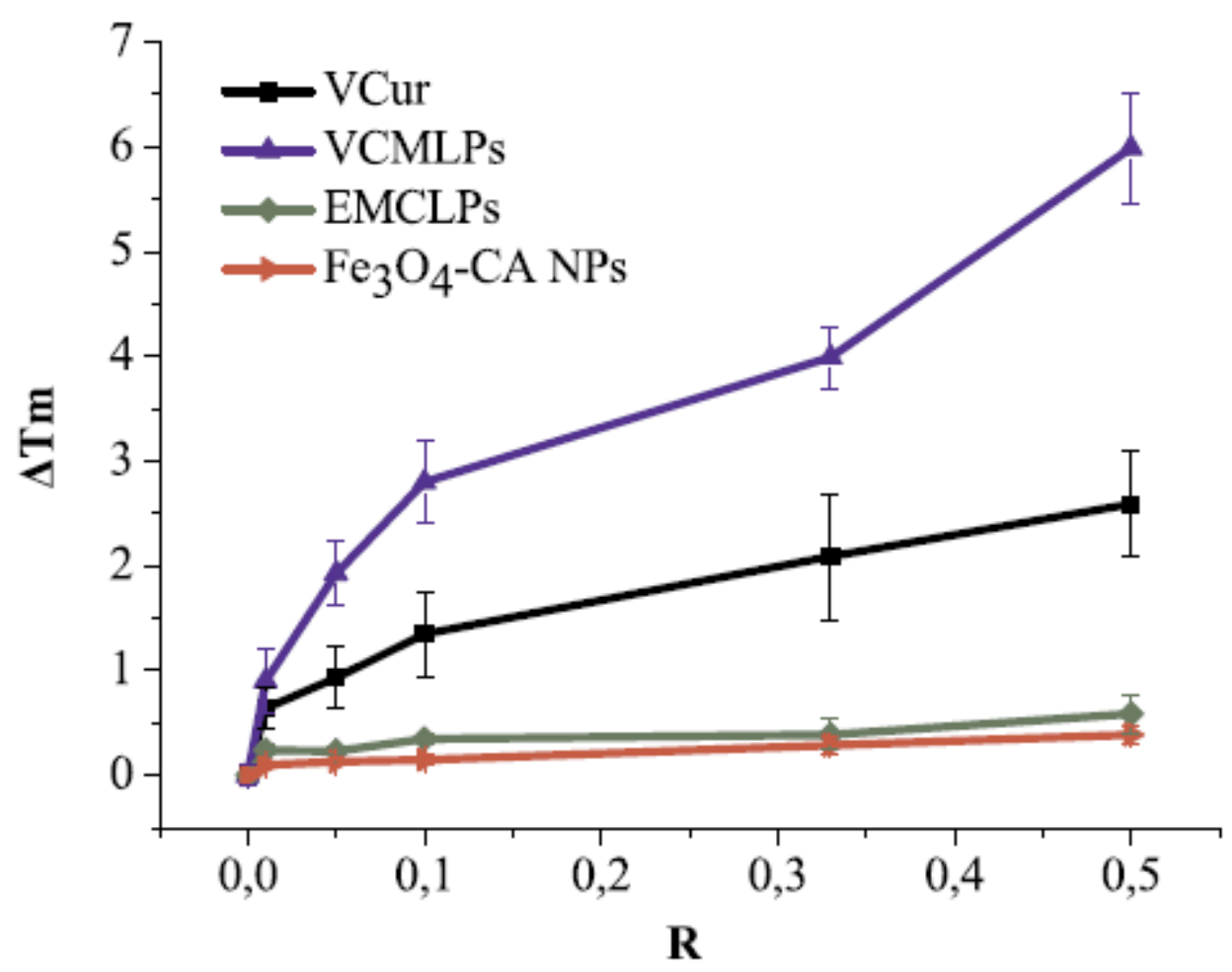

Fig. 16. Thermal denaturation data $(\triangle \mathrm{Tm})$ of CT-DNA $(5 \times 10-5 \mathrm{M})$ upon addition of VCur, VCMCLPs, EMCLPs and Fe304-CA NPs with ratios $\mathrm{R}$ [compound]/[DNA] ranging from 0 to 0.5 .

\subsection{Thermal denaturation studies}

Interactions of small molecules with DNA may alter its melting temperature $(\mathrm{Tm})$ reflecting to some extent the strength and mode of binding [90]. Thermal denaturation experiments were carried out to investigate the effect of VCur and VCMLPs on the stability of the CTDNA duplexes. For CT-DNA alone, under our experimental conditions, a $\mathrm{T}_{\mathrm{m}}$ of $70.35 \pm 0.25^{\circ} \mathrm{C}$ was recorded a value in good agreement with the literature [91]. The addition of increasing concentrations of VCur and VCMLPs $(R=0,0.01,0.05,0.1,0.33,0.5)$ resulted in increased Tm values relative to CT-DNA, reaching at the highest ratio of $R=0.5 \Delta T_{m}$ values of 2.99 and $5.99^{\circ} \mathrm{C}$, respectively (Fig. 16). In the presence of increasing concentrations of Fe3O4-CA NPs and EMCLPs, no significant changes were recorded for the $T_{m}$ values.

\subsection{Fluorescence spectroscopic studies}

Competitive binding experiments, based on the quenching of fluorescence of the known intercalator ethidium bromide (EB) upon displacement from the DNA base pairs and interaction with the solvent molecules, were also run [92]. Fig. 17 shows the effect of increasing concentration of VCur and VCMLPs on the fluorescence intensity of EB bound to CT-DNA. It is obvious from the graph that the fluorescence intensity of DNA-EB reduces upon addition of VCur and VCMLPs and this effect increases with increasing concentration of the above compounds reaching 20 and $28 \%$ for $R=3$, respectively. The substantial decrease in fluorescence intensity of EB indicates that both VCur and VCMLPs displace EB from the base pairs and shows the presence of intercalative binding. It should be noted that the addition of increasing concentrations of Fe304-CA NPs and EMCLPs induce absolutely no displacement of EB bound to CT-DNA. Furthermore, all the studied compounds do not have any effect on the emission of EB in the absence of DNA at all concentrations tested (data nonshown). 


\subsection{Viscosity measurements}

To further investigate the mode of binding of VCur and VCMLPs with CT-DNA, viscosity measurements were carried out. Intercalation of a compound between the DNA base pairs causes unwinding and lengthening of the DNA helix, resulting in changes of the hydrodynamic properties of DNA that can be monitored using viscosity studies [93]. Viscosity measurements were carried out on CT-DNA by varying the concentration of the added compounds to achieve ratios $\mathrm{R}=[$ compound $] /[\mathrm{DNA}]$ of $0,0.01,0.05,0.1,0.2,0.33,0.5$. The values of relative specific viscosity ( $\mathrm{n} / \mathrm{no}) 1 / 3$ (where $\mathrm{n}$ is the viscosity of DNA in the presence of each compound examined and no is the viscosity of DNA alone) were plotted against R according to the theory of Cohen and Eisenberg [53] and are presented in Fig. 18. As can be seen, with increasing amounts of VCur and VCMLPs, the relative viscosity of DNA increases continuously, more profoundly in the case of VCMLPs. The significant increase in DNA viscosity which is comparable to that of known intercalators [92], provides strong evidence for binding to DNA through the intercalation mode. It is obvious from the data in Fig. 18 that the presence of increasing concentrations of Fe3O4-CA NPs and EMCLPs do not alter the effective length of DNA molecule.

\section{Discussion}

LPs constitute a specific category of nanocarriers with exceptional properties in terms of size, biocompatibility, drug loading capacity and surface functionalization, widely used for the encapsulation of therapeutic agents and drugs for cancer treatment. Several research groups have reported the successful encapsulation of anticancer drugs including bleomycin, cisplatin analogues, daunorubicin, doxorubicin in targeted drug delivery liposomal systems [94-98]. CLPs, even though mainly applied as gene delivery systems for transfection due to their ability to be adsorbed onto the surface of the cells and fuse with the negatively charged cellular membranes [99-104], have also been employed for the intracellular delivery of known pharmacophores [105-107] and, more recently, for the delivery of bioactive metal complexes $[41-43,108]$. The embedment of MNPs into the liposomal structure can lead to the development of nano-formulations with magnetic targeting activity for efficient drug release to specific biological sites [109-116]. Within this framework, a homogeneous and welldispersed aqueous suspension of superparamagnetic magnetite NPs surface functionalized with CA, was utilized for the first time, as the magnetic core for the generation of targeted anticancer magnetic cationic liposomal nanocarriers. The VCur complex utilized as the encapsulated molecule, is the third crystallographically reported oxovanadium(IV)-curcumin complex which combines the anticancer potential of curcumin and vanadium in one entity and which has demonstrated anti-ROS, anti-oxidant and DNA degradation activity [36]. However, this is the first time that a metal complex based on curcumin is encapsulated in MCLPs. Both the complete physicochemical characterization of VCur and its demonstrated in vitro activity provide a solid basis for the generation of novel well-characterized nano-formulations with anticancer potential.

Indeed, the hybrid nanocarrier had exceptional stability in physiological media and presented enhanced solubility of the anticancer metallodrug compared to free VCur as evidenced through the entrapment efficiency and loading capacity results and the in vitro release studies. Furthermore, the generated MCLPs preserved the superparamagnetic behavior of the employed MNP core, an advantageous feature for magnetic targeting applications. Even though individual properties may be further optimized, the generated VCMCLPs already meet the physicochemical and morphological requirements for targeted drug delivery applications [117]. 

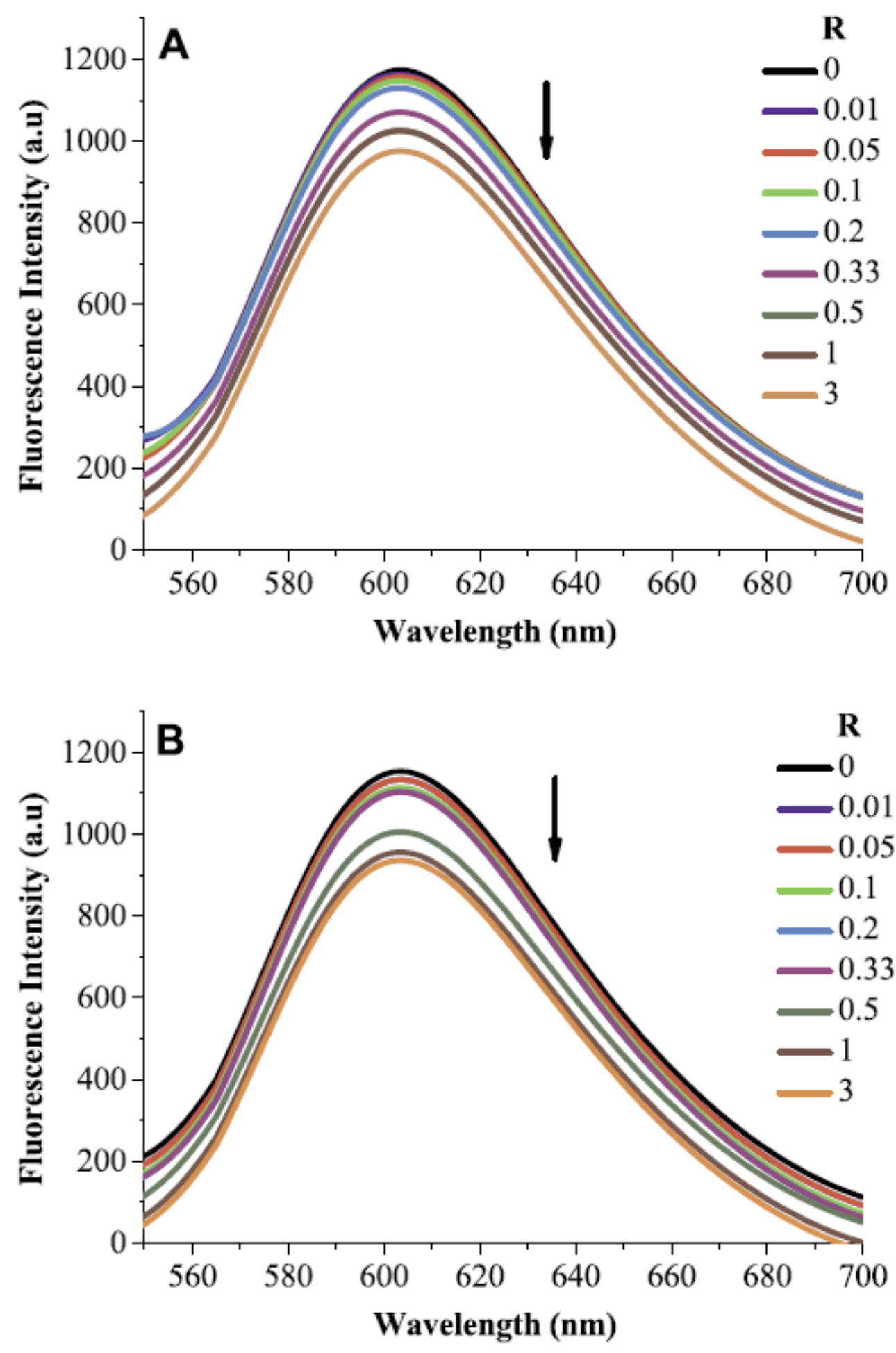

Fig. 17. Emission spectra of the DNA-EB complex ([DNA]:[EB] $=1.3: 1$ ([DNA] $=5 \times 10-5$ and $[E B]=3.85 \times 10-5 \mathrm{M})$ in the presence of increasing concentrations of $A$ ) VCur and $B$ ) VCMCLPs. The employed ratios $\mathrm{R}=[$ compound]/[DNA-EB] are shown on the figure. 


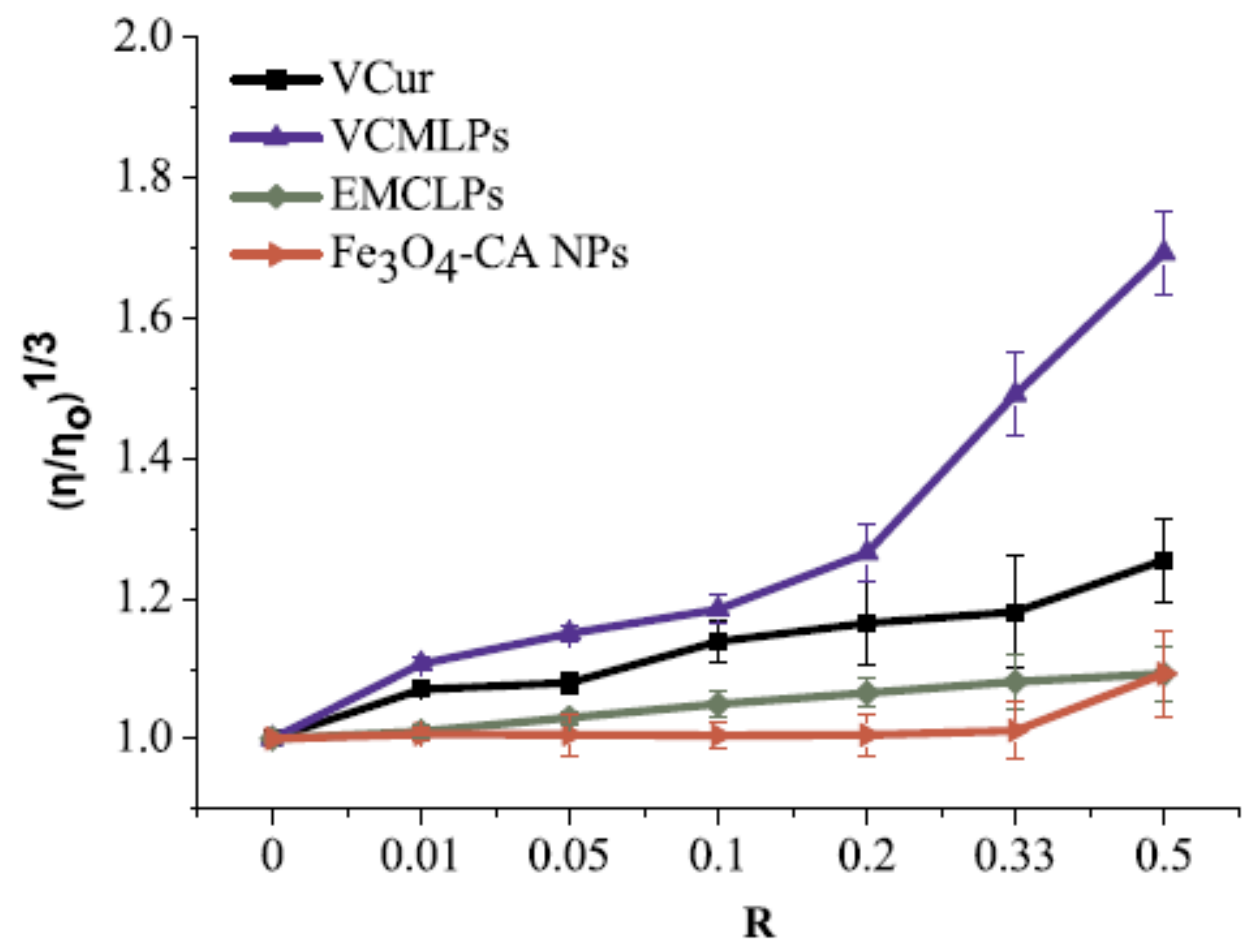

Fig. 18. Effect of increasing amounts of VCur, VCMCLPs, EMCLPs, and $\mathrm{Fe}_{3} \mathrm{O}_{4}-\mathrm{CA}$ NPs on the relative viscosity of $C T-D N A(5 \times 10-5 \mathrm{M})$ at $25{ }^{\circ} \mathrm{C}$ with ratios $\mathrm{R}=$ [compound]/[DNA] ranging from 0 to 0.5 .

Moreover, the biological evaluation of the generated CLPs revealed interesting properties through the studies of their interaction with CTDNA. It is known that CLPs are being investigated as nonviral vectors for the delivery of therapeutic genes, as they bind and condense DNA spontaneously to form CLP-DNA complexes capable of transfecting cells $[118,119]$. At the ratios $R=[\mathrm{VCMCLPs}] /[\mathrm{DNA}]$ of 0.01-0.5 (based on released VCur) employed in our case, no sign of DNA condensation was evident in the $C D$ spectra where the spectral profile of Bform DNA was preserved even at the highest $R=0.5$ showing that the quantity of LPs present has no major effect on DNA structure. The same was observed in the studies with EMCLPs.

The capacity of the VCur cargo to interact with DNA was studied first to serve as base for the assessment of the DNA-binding properties of the MCLPs with the independent biophysical methods of $C D$, DNA melting, fluorescence competitive studies with $E B$, and DNA viscosity measurements. The increase in $\mathrm{Tm}\left(2.99^{\circ} \mathrm{C}\right.$ at $\left.\mathrm{R}=0.5\right)$ indicative of stiffening of the helix, the decrease in EB fluorescence ( $20 \%$ at $R=3$ ) indicative of the displacement of EB from the DNA base pairs, as well as the increase of relative DNA viscosity ( 1.25 at $R=0.5$ ) indicative of DNA elongation, strongly suggest binding of VCur through intercalation. The CD data, despite the lack of major changes, are also in agreement with the intercalative mode of binding through the bathochromic shifts of both positive and negative bands and the lack of an ICD. As curcumin and curcuminoids are groove binders [120-122] and metal complexes containing curcumin as the main organic ligand are also shown to be groove binders [123], intercalation appears to mainly involve the aromatic nitrogen co-ligand 2,2'-bipyridine. Metal complexes with 2,2'-bipyridine and its derivatives in their coordination sphere are known to interact with DNA through intercalation [124-126]. In the case of the VCur complex, concurrent interaction of the complex with the grooves through the coordinated curcumin cannot be excluded, even though groove binding of curcumin and curcumin complexes is usually accompanied by an induced CD signal which was not observed in our case [97]. The effect of VCur on DNA, especially in relation to the viscosity data, appears to be more pronounced than that displayed by other oxovanadium(IV) complexes in the literature suggested to interact through the intercalative mode $[34,127,128]$, as 
well as other curcumin/curcuminoid complexes with intercalation potential $[125,129,130]$. Even though literature comparisons are not always exact due to differences in experimental details and handling, the relatively strong DNA interaction displayed by VCur is worth highlighting. The data on the action of VCur on DNA are in agreement with our previous findings on the involvement of VCur in genotoxic effects, namely, lethal DNA damage in Escherichia coli [36].

The DNA interaction data from all biophysical assays were much more pronounced when the VCMCLPs were used. As the VCMLPs alone at the concentrations employed do not cause any effect on DNA in all assays, the enhanced interaction necessarily involves the VCur complex, the action of which is enhanced when administered as the liposomal cargo. The higher VCur effect observed with the VCMCLPs may be attributed to electrostatic interactions between the positively charged LPs and the negatively charged phosphate backbone of DNA, which result in accumulation of the LPs in the vicinity of DNA and consequent increase of the local effective concentration of VCur released at the DNA site. Electrostatic interactions have been employed to bind positively charged NPs on DNA for a variety of biological applications, like inhibition of DNA polymerase action or functional DNA recognition by proteins [131]. To our knowledge this is the only work suggesting that positively charged liposomal NPs generate increased concentration of their cargo at the DNA site, offering a further dimension in the importance of CLPs as nanocarriers.

\section{Conclusions}

In the pursuit of the development of advanced type of long-life, stable, bioavailable nanocarriers of vanadium metallodrugs, containing metal-bound natural substrates such as curcumin, novel VCurloaded cationic targeted-magnetoliposomes were synthesized, physicochemically characterized and biologically evaluated as DNA binding agents. The biocompatible and bioavailable nature of the emerged liposomal nano-formulations, their magnetic targeting potential, and their capacity to favorably interact with DNA indicate the ability of LPs to function as efficient nanocarriers of bioactive metal complexes, and render them ideal nano-platforms for further investigations towards therapeutic applications against cancer.

\section{Abbreviation list}

MNPs Magnetic nanoparticles

NPs Nanoparticles

SPIO Superparamagnetic iron oxide

LPs Liposomes

MLPs Magnetoliposomes

CLPs Cationic LPS

PDT Photodynamic therapy

ROS Reactive oxygen species

VCur V(IV)-curcumin-bipyridine complex

PBS Phosphate buffered saline

NF-KB Nuclear factor kappa-light-chain-enhancer of activated Bcells

Bcl2 B-cell lymphoma 2

BcIXL B-cell lymphoma-extra large

COX-2 Cyclooxygenase-2

DOTAP N-[1-(2,3-dioleoyloxy)propyl]- N,N,N-trimethylammonium

EPC Egg L- $\alpha$-phosphatidylcholine

MCLPs Magnetic cationic liposomes

CA Citric acid

MNPs Magnetite $\left(\mathrm{Fe}_{3} \mathrm{O}_{4}-\mathrm{CA}\right)$ colloidal magnetic NPs 
EMCLPs Empty magnetic cationic liposomes

VCMCLPs VCur-loaded magnetic cationic liposomes

$\mathrm{MeOH}$ Methanol

EtOH Ethanol

CT Calf thymus

DMSO Dimethyl sulfoxide

FT-IR Fourier Transform-Infrared spectroscopy

XRD X-ray diffraction

HRTEM High resolution transmission electron microscopy

TEM Transmission electron microscopy

XPS X-ray photoelectron spectroscopy

SEM Scanning electron microscopy

EDX Energy dispersive X-ray

DLS Dynamic Light Scattering

TGA Thermogravimetric Analysis

FAAS Flame atomic absorption spectrophotometry

HPLC High Performance Liquid Chromatography

DAD Diode array detector

UV UV-Visible

$\mathrm{T}_{\mathrm{t}} \quad$ Main phase transition temperature

PTFE Polytetrafluoroethylene

SD Standard deviation

MLVs Multilamellar vesicles

SUVs Small unilamellar vesicles

ABS Absorbance

CD Circular dichroism

$\mathrm{T}_{\mathrm{m}} \quad$ Melting temperature

EB Ethidium bromide

Declaration of Competing Interest

No conflict of interest was declared by the authors.

\section{Acknowledgments}

The authors thank Dr. Theodoros Papadopoulos, Senior Lecturer, University of Chester, U.K. for helpful discussions at the initial stage of this work. Dr. E. Halevas gratefully acknowledges financial support by Stavros Niarchos Foundation (SNF), Greece (https://www.snf.org/) through implementation of the program of Industrial Fellowships at NCSR "Demokritos".

\section{References}

[1] C. Moorthi, R. Manavalan, K. Kathiresan, J. Pharm. Pharmaceut. Sci. 14 (2011) 67-77.

[2] J.Q. Zhang, Z.R. Zhang, H. Yang, Q.Y. Tan, S.R. Qin, X.L. Qiu, Pharm. Res. 22 (2005) 573-583.

[3] C. Alexiou, W. Arnold, R.J. Klein, F.G. Parak, P. Hulin, C. Bergemann, W. Erhardt, S. Wagenpfeil, A.S. Lubbe, Cancer Res. 60 (2000) 6641-6648.

[4] C. Alexiou, R. Jurgons, R.J. Schmid, C. Bergemann, J. Henke, W. Erhardt, E. Huenges, F. Parak, J. Drug Target. 11 (2003) 139-149.

[5] M. Babincova, V. Altanerova, C. Altaner, P. Cicmanec, P. Babinec, Med. Phys. 31 (2004) 22192221.

[6] J. Huang, Y. Li, A. Orza, Q. Lu, P. Guo, L. Wang, L. Yang, H. Mao, Adv. Funct. Mater. (2016) 38183836. 
[7] A.S. Mikhail, A. Partanen, P. Yarmolenko, A.M. Venkatesan, B.J. Wood, Magn. Reson. Imaging Clin. N. Am. 23 (2015) 643-655.

[8] K.J. Widder, A.E. Senyei, D.F. Ranney, Adv. Pharmacol. Chemother. 16 (1979) 213-271.

[9] A.S. Lubbe, C. Bergemann, J. Brock, D.G. McClure, J. Magn. Magn. Mater. 194 (1999) 149-155.

[10] Y.W. Jun, J.H. Lee, J. Cheon, Angew. Chem. Int. Ed. 47 (2008) 5122-5135.

[11] H.B. Na, I.C. Song, T. Hyeon, Adv. Mater. 21 (2009) 2133-2148.

[12] C. Corot, P. Robert, J.M. Idee, M. Port, Adv. Drug Deliv. Rev. 58 (2006) 1471-1504.

[13] N.V.S. Vallabani, S. Singh, 3 Biotech. 8 (2018) 279.

[14] J. Chomoucka, J. Drbohlavova, D. Huska, V. Adam, R. Kizek, J. Hubalek, Pharmacol. Res. 62 (2010) 144-149.

[15] A.S. Wadajkar, J.U. Menon, T. Kadapure, R.T. Tran, J. Yang, K.T. Nguyen, Recent Pat. Biomed. Eng. 6 (2013) 47-57.

[16] A. La Porta, A. Sanchez-Iglesias, T. Altantzis, S. Bals, M. Grzelczak, L.M. Liz- Marzan, Nanoscale, 7 (2015) 10377-10381.

[17] M. Mahmoudi, S. Sant, B. Wang, S. Laurent, T. Sen, Adv. Drug Deliv. Rev. 63 (2011) 24-46.

[18] D.L. Thorek, A.K. Chen, J. Czupryna, A. Tsourkas, Ann. Biomed. Eng. 34 (2006) 23-38.

[19] K. Hayashi, K. Ono, H. Suzuki, M. Sawada, M. Moriya, W. Sakamoto, T. Yogo, ACS Appl. Mater. Interfaces 2 (2010) 1903-1911.

[20] D.D. Lasic, N.S. Templeton Adv, Drug Deliv. Rev. 20 (1996) 221-226.

[21] S. Przestalski, J. Sarapuk, H. Kleszczyńska, J. Gabrielska, J. Hladyszowski, Z. Trela, J. Kuczera, Acta Biochim. Pol. 47 (2000) 627-638.

[22] S. Nappini, F.B. Bombelli, M. Bonini, B. Norden, P. Baglioni, Soft Matter 6 (2010) 154-162.

[23] C.A. Monnier, D. Burnard, B. Rothen-Rutishauser, M. Lattuada, A. Petri-Fink, Eur. J. Nanomed. 6 (2014) 201-215.

[24] D.R. Khan, M.N. Webb, T.H. Cadotte, M.N. Gavette, Breast Cancer (Auckl), 9 (2) (2015) 1-5 Suppl.

[25] R. Kunstfeld, G. Wickenhauser, U. Michaelis, M. Teifel, W. Umek, K. Naujoks, K. Wolff, P. Petzelbauer, J. Invest. Dermatol. 120 (2003) 476-482.

[26] S. Strieth, M.E. Eichhorn, B. Sauer, B. Schulze, M. Teifel, U. Michaelis, M. Dellian, Int. J. Cancer 110 (2004) 117-124.

[27] G. Thurston, J.W. McLean, M. Rizen, P. Baluk, A. Haskell, T.J. Murphy, D. Hanahan, D.M. McDonald, J. Clin. Invest. 101 (1998) 1401-1413.

[28] K. Kostarelos, A.D. Miller, Chem. Soc. Rev. 34 (2005) 970-994.

[29] R.B. Campbell, D. Fukumura, E.B. Brown, L.M. Mazzola, Y. Izumi, R.K. Jain, V.P. Torchilin, L.L. Munn, Cancer Res. 62 (2002) 6831-6836.

[30] P.S. Williams, F. Carpino, M. Zborowski, Mol. Pharm 6 (2009) 1290-1306.

[31] S. Wanninger, V. Lorenz, A. Subhan, F.T. Edelmann, Chem. Soc. Rev. 44 (2015) 4986-5002.

[32] S.S. Bansal, M. Goel, F. Aqil, M.V. Vadhanam, R.C. Gupta, Cancer Prev. Res. (Phila.) 4 (2011) 1158-1171.

[33] B. Banik, K. Somyajit, G. Nagaraju, A.R. Chakravarty, Dalton Trans. 43 (2014) 13358-13369.

[34] B. Balaji, B. Balakrishnan, S. Perumalla, A.A. Karande, A.R. Chakravarty, Eur. J. Med. Chem. 85 (2014) 458-467.

[35] S. Banerjee, P. Prasad, A. Hussain, I. Khan, P. Kondaiah, A.R. Chakravarty, Chem. Comm. 48 (2012) 7702-7704.

[36] E. Halevas, T.A. Papadopoulos, C.H. Swanson, G.C. Smith, A. Hatzidimitriou, G. Katsipis, A. Pantazaki, I. Sanakis, G. Mitrikas, K. Ypsilantis, G. Litsardakis, A. Salifoglou, J. Inorg. Biochem. 191 (2019) 94-111.

[37] T. Feng, Y. Wei, R.J. Lee, L. Zhao, Int. J. Nanomedicine 12 (2017) 6027-6044.

[38] M. Mahmud, A. Piwoni, N. Filipczak, M. Janicka, J. Gubernator, PLoS ONE 12 (2017) e0173728.

[39] A.K. Panda, D. Chakraborty, I. Sarkar, T. Khan, G. Sa, J. Exp. Pharmacol. 9 (2017) 31-45. 
[40] D. Baczynska, K. Widerak, M. Ugorski, M. Langner, Zeitschrift fur Naturforschung C 56 (2001) 872-877.

[41] G. Vitiello, A. Luchini, G. D’Errico, R. Santamaria, A. Capuozzo, C. Irace, D. Montesarchio, L. Paduano, J. Mater. Chem. B 3 (2015) 3011-3023.

[42] G. Mangiapia, G. Vitiello, C. Irace, R. Santamaria, A. Colonna, R. Angelico, A. Radulescu, G. D'Errico, D. Montesarchio, L. Paduano, Biomacromolecules 14 (2013) 2549-2560.

[43] D. Montesarchio, G. Mangiapia, G. Vitiello, D. Musumeci, C. Irace, R. Santamaria, G. D'Errico, L. Paduano, Dalton Trans. 42 (2013) 16697-16708.

[44] C. Riccardi, D. Musumeci, C. Irace, L. Paduano, D. Montesarchio, Eur. J. Org. Chem. 7 (2017) 1100-1119.

[45] C. Irace, G. Misso, A. Capuozzo, M. Piccolo, C. Riccardi, A. Luchini, M. Caraglia, L. Paduano, D. Montesarchio, R. Santamaria, Sci. Rep. 7 (2017) 45236.

[46] J. Marmur, J. Mol. Biol. 3 (1961) 208-218.

[47] J.H. Scofield, J. Electron Spectroscoc. Relat. Phenom. 8 (1976) 129-137.

[48] J.-C. Colas, W. Shi, V.S.N. Malleswara Rao, A. Omri, M. Reza Mozafari, H. Singh, Micron. 38 (2007) 841-847.

[49] S.Y. Yang, Y. Zheng, J.Y. Chen, Q.Y. Zhang, D. Zhao, D.E. Han, C.J. Chen, Colloids Surf. B Biointerfaces. 101 (2013) 6-13.

[50] Y. Zhang, H. Li, J. Sun, J. Gao, W. Liu, B. Li, Y. Guo, J. Chen, Int. J. Pharm. 390 (2010) 198-207. [51] A.E. Regelin, S. Fankhaenel, L. Gurtesch, C. Prinz, G. von Kiedrowski, U. Massing, Biochim. Biophys. Acta 1464 (2000) 151-164.

[52] L. Clesceri, A. Greenberg, R. Trussell, Standard Methods for the Examination of Water and Wastewater, 17th edition, APHA-AWWA-WEF, Washington DC, 1989.

[53] G. Cohen, H. Eisengerg, Biopolymers. 8 (1969) 45-55.

[54] R. Massart, IEEE Trans. Magn. 17 (1981) 1247-1248.

[55] S. Lefebure, E. Dubois, V. Cabuil, S. Neveu, R. Massart, J. Mater. Res. 13 (1998) 2975-2981.

[56] Z. Sun, F. Su, W. Forsling, P. Samskog, J. Colloid Interface Sci. 197 (1998) 151-159.

[57] M. Elisa de Sousa, M.B. Fernandez van Raap, P.C. Rivas, P. Mendoza Zelis, P. Girardin, G.A.

Pasquevich, J.L. Alessandrini, D. Muraca, F.H. Sanchez, J. Phys. Chem. C 117 (2013) 5436-5445.

[58] S. Gil, E. Castro, J.F. Mano, Mater. Lett. 100 (2013) 266-270.

[59] Y. Sahoo, A. Goodarzi, M.T. Swihart, T.Y. Ohulchanskyy, N. Kaur, E.P. Furlani, P.N. Prasad, Aust. J. Chem. B 109 (2005) 3879-3885.

[60] S. Nigam, K.C. Barick, D. Bahadur, J. Magn. Magn. Mater. 323 (2011) 237-243.

[61] M. Răcuciu, D.E. Creangă, A. Airinei, Eur. Phys. J. E 21 (2006) 117-121.

[62] N. Kallay, E. Matijevic, Langmuir 1 (1985) 195-201.

[63] D.S. Todorovsky, D.G. Dumanova, R.V. Todorovska, M.M. Getsova, Croat. Chem. Acta 75 (2002) 155-164.

[64] E. Cheraghipour, S. Javadpour, A.R. Mehdizadeh, J. Biomed. Sci. Eng. 5 (2012) 715-719.

[65] L. Levy, Y. Sahoo, K. Kim, E.J. Bergey, P.N. Prasad, Chem. Mater. 14 (2002) 3715-3720.

[66] K.M. Krishnan, IEEE Trans. Magn. 7 (2010) 2523-2558.

[67] A.K. Gupta, M. Gupta, Biomaterials 26 (2005) 3995-4021.

[68] B.D. Cullity, C.D. Graham, Introduction to Magnetic Materials, 2nd edition, Wiley, 2009.

[69] R. Frison, G. Cernuto, A. Cervellino, O. Zaharko, G.M. Colonna, A. Guagliardi, N. Masciocchi, Chem. Mater. 25 (2013) 4820-4827.

[70] X. Batlle, N. Perez, P. Guardia, O. Iglesias, A. Labarta, F. Bartolome, L.M. Garcia, J. Bartolome, A.G. Roca, M.P. Morales, C.J. Serna, J. Appl. Phys. 109 (2011) 07B524.

[71] M. Circu, A. Nan, G. Borodi, J. Liebscher, R. Turcu, Nanomaterials 6 (2016) 228.

[72] J.K. Lim, S.P. Yeap, H.X. Che, S.C. Low, Nanoscale Res. Lett. 8 (2013) 381.

[73] T. Phenrat, N. Saleh, K. Sirk, R.D. Tilton, G.V. Lowry, Environ. Sci. Technol. 41 (2007) 284-290.

[74] L. Shen, A. Stachowiak, S.E.K. Fateen, P.E. Laibinis, T.A. Hatton, Langmuir 17 (2001) 288-299.

[75] S. Dandamudi, R.B. Campbell, Biochim. Biophys. Acta 1768 (2007) 427-438. 
[76] A. Akbarzadeh, R. Rezaei-Sadabady, S. Davaran, S. Woo Joo, N. Zarghami, Y. Hanifehpour, M. Samiei, M. Kouhi, K. Nejati-Koshki, Nanoscale Res. Lett. 8

(2013) 102.

[77] T. Nawroth, M. Rusp, R.P. May, Physica B 350 (2004) E635-E638.

[78] H.R. Samadikhah, A. Majidi, M. Nikkhah, S. Hosseinkhani, Int. J. Nanomedicine 6 (2011) 22752283.

[79] K.C. Barick, M. Aslam, Y.-P. Lin, D. Bahadur, P.V. Prasad, V.P. Dravid, J. Mater. Chem. 19 (2009) 7023.

[80] J. Wan, W. Cai, X. Meng, E. Liu, Chem. Commun. (2007) 5004.

[81] Y. Sun, L. Duan, Z. Guo, Y. DuanMu, M. Ma, L. Xu, Y. Zhang, N. Gu, J. Magn. Magn. Mater. 285 (2005) 65-70.

[82] K.N. Kontogiannopoulos, S.K. Tsermentseli, A.N. Assimopouloy, V.P. Papageorgioy, J. Liposome Res. 24 (2014) 230-240.

[83] D.G. Fatouros, S.G. Antimisiaris, J. Colloid Interface, Sci. 251 (2002) 271-277.

[84] E. Alexopoulou, A. Georgopoulos, K.A. Kagkadis, C. Demetzos, J. Liposome Res. 16 (2006) 17-25.

[85] D. Yokota, M. Moraes, S.C. Pinho, Braz. J. Chem. Eng. 29 (2012) 325-335.

[86] C. Duval, Inorganic Thermogravimetric Analysis, Second and Revised edition, Elsevier Publishing Co., Amsterdam, 1963, pp. 294-300.

[87] M.J.W. Johnston, S.C. Semple, S.K. Klimuk, K. Edwards, M.L. Eisenhardt, E.C. Leng, G. Karlsson, D. Yanko, P.R. Cullis, Biochim. Biophys. Acta, Biomembr. 1758 (2006) 55-64.

[88] J.C. Pessoa, I. Correia, G. Goncalves, I. Tomaz, J. Argent. Chem. Soc. 97 (2009) 151-165.

[89] V.I. Ivanov, L.E. Minchenk, A.K. Schyolki, A.I. Poletaye, Biopolymers. 12 (1973) 89-110.

[90] B. Mavroidi, M. Sagnou, K. Stamatakis, M. Paravatou-Petsotas, M. Pelecanou, C. Methenitis, Inorg. Chim. Acta 444 (2016) 63-75.

[91] W.B. Melchior, P. Vonhippe, Proc Natl Acad Sci U S A 70 (1973) 298-302.

[92] J.B. LePecq, C. Paoletti, J. Mol. Biol. 27 (1967) 87-106.

[93] D. Suh, J.B. Chaires, Bioorg. Med. Chem. 3 (1995) 723-728.

[94] K. Meyer, 77th Annual Clinical Congress, Oct. 21-24, Chicago, IL, (1991).

[95] J.M. Waterhouse, D.S. Minors, B. Lemmer (Ed.), Chronopharmacology: Cellular and Biochemical Interactions, Dekker, New York, 1989, pp. 35-50.

[96] R. Smaaland, A.M. Svardal, K. Lote, M. Ueland, O.D. Laerum, J. Natl. Cancer Inst. 83 (1991)

1092-1098.

[97] A. Reinberg, M.H. Smolensky, Clin. Pharmacokinet. 7 (1982) 401-420.

[98] A.S. Lubbe, C. Alexiou, C. Bergemann, J, Surg, Res. 95 (2001) 200-206.

[99] L.H. Li, S.W. Hui, Biochim. Biophys. Acta 1323 (1997) 105-116.

[100] K. Stebelska, P. Wyrozumska, A.F. Sikorski, Chem. Biol. Interact. 160 (2006) 165-174.

[101] Y. Obata, S. Tajima, S. Takeoka, J. Control. Release 142 (2010) 267-276.

[102] R.B. Campbell, B. Ying, G.M. Kuesters, R. Hemphill, J. Pharm. Sci. 98 (2009) 411-429.

[103] W. Zhao, S. Zhuang, X.R. Qi, Int. J. Nanomedicine 6 (2011) 3087-3098.

[104] A.S. Abu Lila, S. Kizuki, Y. Doi, T. Suzuki, T. Ishida, H. Kiwada, J. Control. Release 137 (2009) 814.

[105] S.I. Kim, D. Shin, T.H. Choi, J.C. Lee, G.J. Cheon, K.Y. Kim, M. Park, M. Kim, Mol. Ther. 15 (2007) 1145-1152.

[106] R. Ramesh, T. Saeki, N.S. Templeton, L. Ji, L.C. Stephens, I. Ito, D.R. Wilson, Z. Wu, C.D. Branch, J.D. Minna, J.A. Roth, Mol. Ther. 3 (2001) 337-350.

[107] Y. Zhang, E.L. Bradshaw-Pierce, A. Delille, D.L. Gustafson, T. J. J. Pharm. Sci. 97 (2008) 237-250.

[108] S. Ibrahim, T. Tagami, T. Ozeki, Biol. Pharm. Bull. 40 (2017) 815-823.

[109] E. Viroonchatapan, M. Ueno, H. Sato, I. Adachi, H. Nagae, K. Tazawa, I. Horikoshi, Pharm. Res. 12 (1995) 1176-1183.

[110] J.W.M. Bulte, L.D. Ma, R.L. Magin, R.L. Kamman, C.E. Hulstaert, K.G. Go, T.H. The, L. de Leij, Magn. Reson. Med. 29 (1993) 32-37. 
[111] M.S. Martina, J.P. Fortin, C. Menager, O. Clement, G. Barratt, C. Grabielle-Madelmont, F. Gazeau, V. Cabuil, S. Lesieur, J. Am. Chem. Soc. 127 (2005)

10676-10685.

[112] J.A. Dagata, N. Farkas, C.L. Dennis, R.D. Shull, V.A. Hackley, C. Yang, K.F. Pirollo, E.H. Chang, Nanotechnology 19 (2008) 305101.

[113] V. Plassat, M.S. Martina, G. Barratt, C. Menager, S. Lesieur, Int. J. Pharm. 34 (2007) 118-127.

[114] O. Veiseh, J.W. Gunn, M. Zhang, Adv. Drug Deliv. Rev. 62 (2010) 284-304.

[115] S. Dandamudi, R.B. Campbell, Biomaterials 28 (2007) 4673-4683.

[116] A. Skouras, K. Papadia, S. Mourtas, P. Klepetsanis, S.G. Antimisiaris, Eur. J. Pharm. Sci. 123

(2018) 162-172.

[117] Z.P. Aguilar, Targeted drug delivery, Nanomaterials for Medical Applications, 2013, pp. 181234.

[118] S. Simoes, A. Filipe, H. Faneca, M. Mano, N. Penacho, N. Duzgunes, M.P. de Lima, Expert Opin. Drug Deliv. 2 (2005) 237-254.

[119] S.J. Ryhanen, M.J. Saily, T. Paukku, S. Borocci, G. Mancini, J.M. Holopainen, P.K.J. Kinnunen, Biophys. J. 84 (2003) 578-587.

[120] F. Zsila, Z. Bikadi, M. Simonyi, Org. Biomol. Chem. 2 (2004) 2902-2910.

[121] A. Kunwar, E. Simon, U. Singh, R.K. Chittela, D. Sharma, S.K. Sandur, I.K. Priyadarsini, Chem.

Biol. Drug Des. 77 (2011) 281-287.

[122] B.K. Sahoo, K.S. Ghosh, R. Bera, S. Dasgupta, Chem. Phys. 351 (2008) 163-169.

[123] J. Rajesh, M. Rajasekaran, G. Rajagopal, P. Athappan, Spectrochim. Acta A 97 (2012) 223-230.

[124] D. Pucci, T. Bellini, A. Crispini, I. D’Agnano, P.F. Liguori, P. Garcia-Orduna, S. Pirillo, A. Valentini, G. Zanchetta, Med. Chem. Commun. 3 (2012) 462-468.

[125] M. Cusumano, M.L. Di Pietro, A. Giannetto, P.A. Vainiglia, J. Inorg. Biochem. 99 (2005) 560565.

[126] A.A. Baroud, L.E. Mihajlovic-Lalic, N. Gligorijevic, S. Arandelovic, D. Stankovic, S. Radulovic, K. Van Hecke, A. Savic, S. Grguric-Sipka, J. Coord. Chem. 70 (2017) 831-847.

[127] I. Correia, S. Roy, C.P. Matos, S. Borovic, N. Butenko, I. Cavaco, F. Marques, J. Lorenzo, A. Rodriguez, V. Moreno, J.C. Pessoa, J. Inorg. Biochem. 147 (2015) 134-146.

[128] M.N. Patel, M.R. Chhasatia, S.H. Patel, H.S. Bariya, V.R. Thakkar, J. Enzym. Inhib. Med. Chem. 24 (2009) 715-721.

[129] J. Annaraj, S. Srinivasan, K.M. Ponvel, P. Athappan, J. Inorg. Biochem. 99 (2005) 669-676.

[130] N. Shahabadi, M. Falsafi, N.H. Moghadam, J. Photochem. Photobiol. B 122 (2013) 45-51.

[131] D.F. Moyano, V.M. Rotello, Langmuir 27 (2011) 10376-10385. 